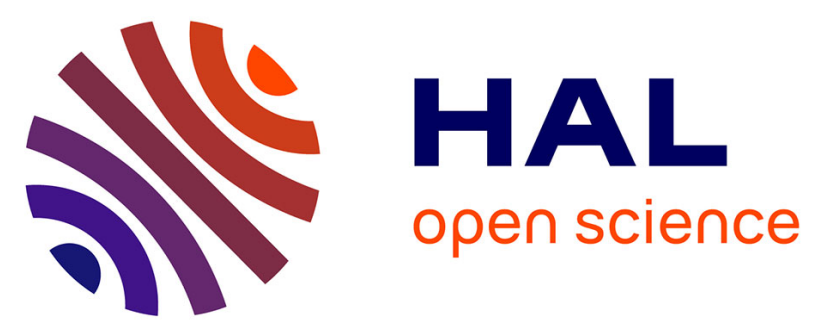

\title{
Origin of silica in rice plants and contribution of diatom Earth fertilization: insights from isotopic Si mass balance in a paddy field
}

\author{
Jean Riotte, Kollalu Sandhya, Nagabovanalli B. Prakash, Stephane Audry, \\ Thomas Zambardi, Jerome Chmeleff, Sriramulu Buvaneshwari, \\ Jean-Dominique Meunier
}

\section{To cite this version:}

Jean Riotte, Kollalu Sandhya, Nagabovanalli B. Prakash, Stephane Audry, Thomas Zambardi, et al.. Origin of silica in rice plants and contribution of diatom Earth fertilization : insights from isotopic Si mass balance in a paddy field. Plant and Soil, 2018, 423 (1-2), pp.481-501. 10.1007/s11104-017-3535z . hal- 01765567

\section{HAL Id: hal-01765567 https://hal.science/hal-01765567}

Submitted on 29 Mar 2019

HAL is a multi-disciplinary open access archive for the deposit and dissemination of scientific research documents, whether they are published or not. The documents may come from teaching and research institutions in France or abroad, or from public or private research centers.
L'archive ouverte pluridisciplinaire $\mathbf{H A L}$, est destinée au dépôt et à la diffusion de documents scientifiques de niveau recherche, publiés ou non, émanant des établissements d'enseignement et de recherche français ou étrangers, des laboratoires publics ou privés. 
Origin of silica in rice plants and contribution of diatom earth fertilization: insights from isotopic Si mass balance in a paddy field

\author{
Jean Riotte ${ }^{1,2^{*}}$, Kollalu Sandhya ${ }^{3}$, Nagabovanalli B. Prakash ${ }^{3}$, Stéphane Audry ${ }^{1}$, Thomas
} Zambardi $^{1}$, Jérôme Chmeleff ${ }^{1}$, Sriramulu Buvaneshwari ${ }^{4}$ Jean-Dominique Meunier $^{5}$

(*) Corresponding author: jean.riotte@ird.fr

1- Géosciences Environnement Toulouse (Université Paul-Sabatier, IRD, CNRS), 14 avenue E. Belin, 31400 Toulouse, France

2- Indo-French Cell for Water Sciences, IRD-Indian Institute of Science, Bangalore 560012 India

3- University of Agricultural Sciences, GKVK, Bangalore, India

4- (1) Indian Institute of Science, Department of Civil Engineering, 560012 Bengaluru, India

5- Aix Marseille Univ, CNRS, IRD, Coll France, CEREGE, 13545 Aix-en-Provence cedex 04, France

\title{
Abstract
}

\section{Background and aims}

The benefits of $\mathrm{Si}$ for crops is well evidenced but the biogeochemical cycle of $\mathrm{Si}$ in agriculture remains poorly documented. This study aims at identifying and quantifying the Si sources (primary and secondary soil minerals, amorphous silica, irrigation, Si-fertilizer) to rice plants.

\section{Method}

Field experiments were carried out with and without application of diatomaceous earth (DE) under rice and bare conditions to determine the water and dissolved mass balance in paddy fields (Karnataka, Southern India). The fate of the Si brought by irrigation (DSi) (uptake by rice, uptake by diatoms, adsorption) was assessed through a solute mass balance combined with silicon isotopic signatures.

Results

Above the ground-surface, about one third of the DSi flux brought by borewell irrigation (545 mmol Si.m $\mathrm{m}^{-2}$ ) to bare plots and half of DSi in rice plots were removed from solution within minutes or hours following irrigation. Such rate is consistent with the rate of DSi adsorption onto Fe-oxyhydroxides but not with diatom blooms. In rice and rice+DE experiments, the 


\section{Figure 1}
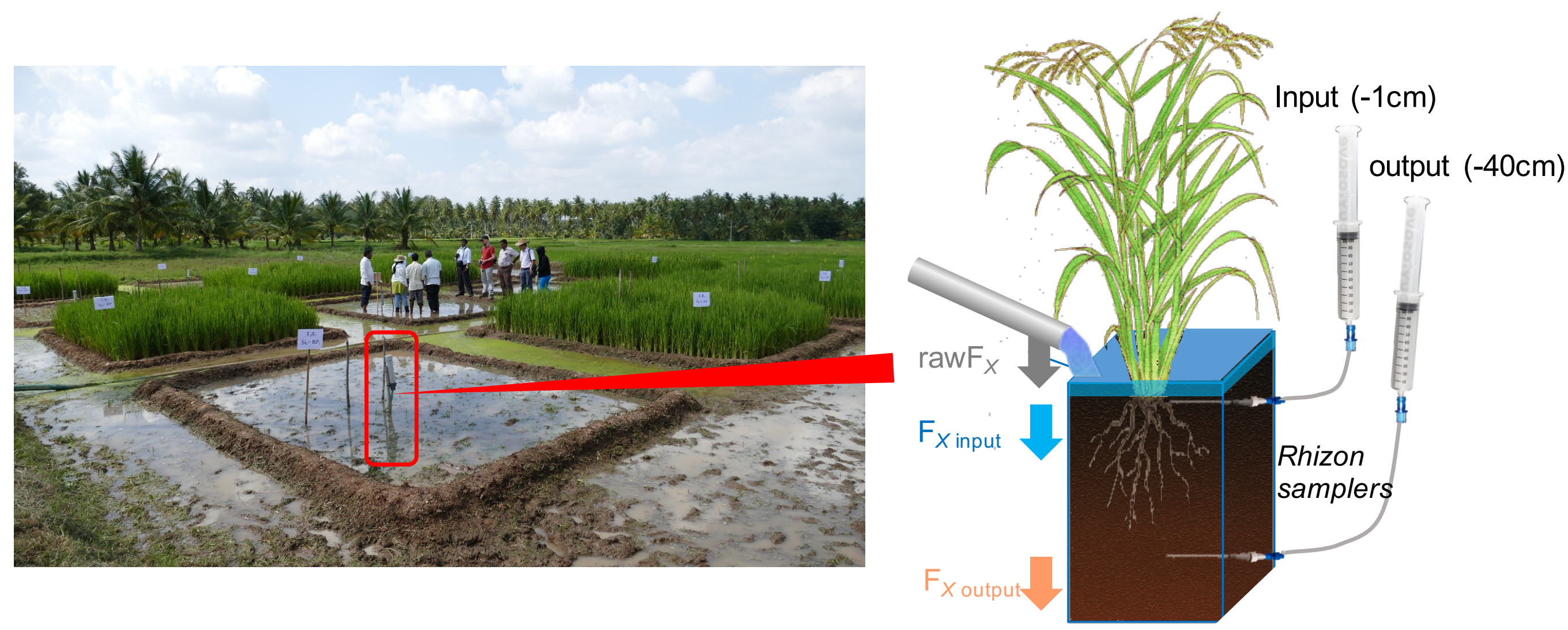


\section{Figure 2}
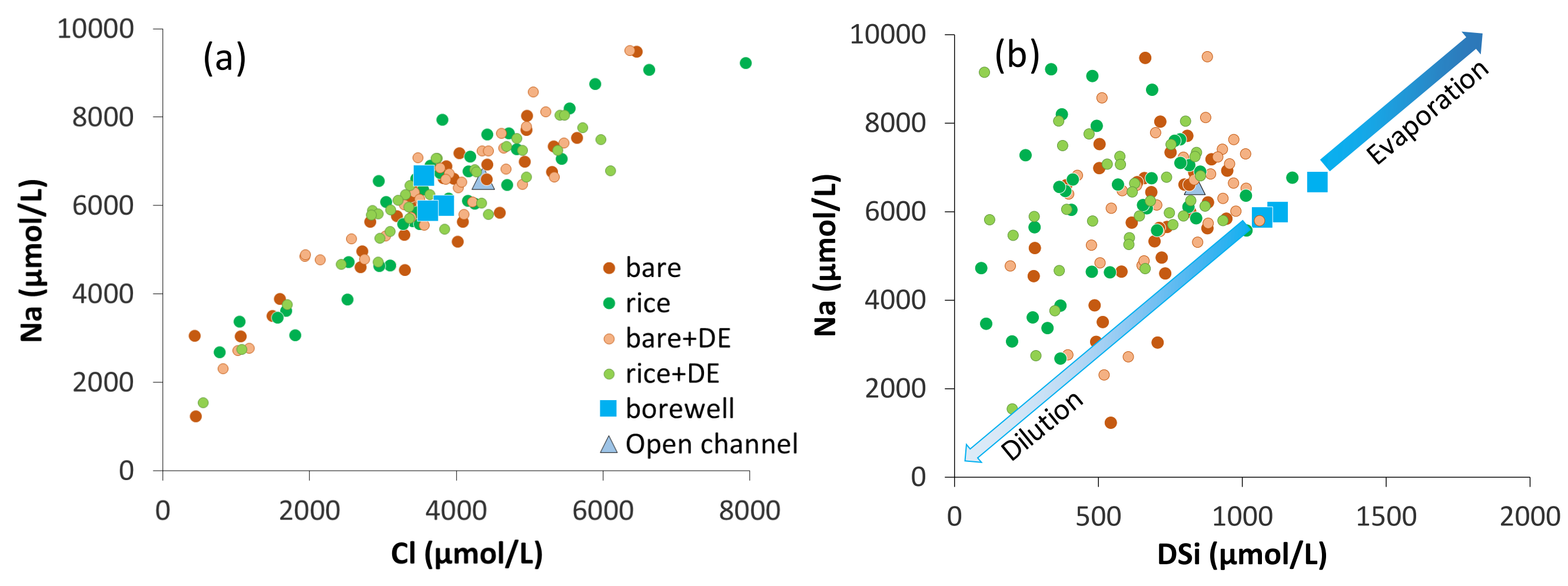
Figure 2
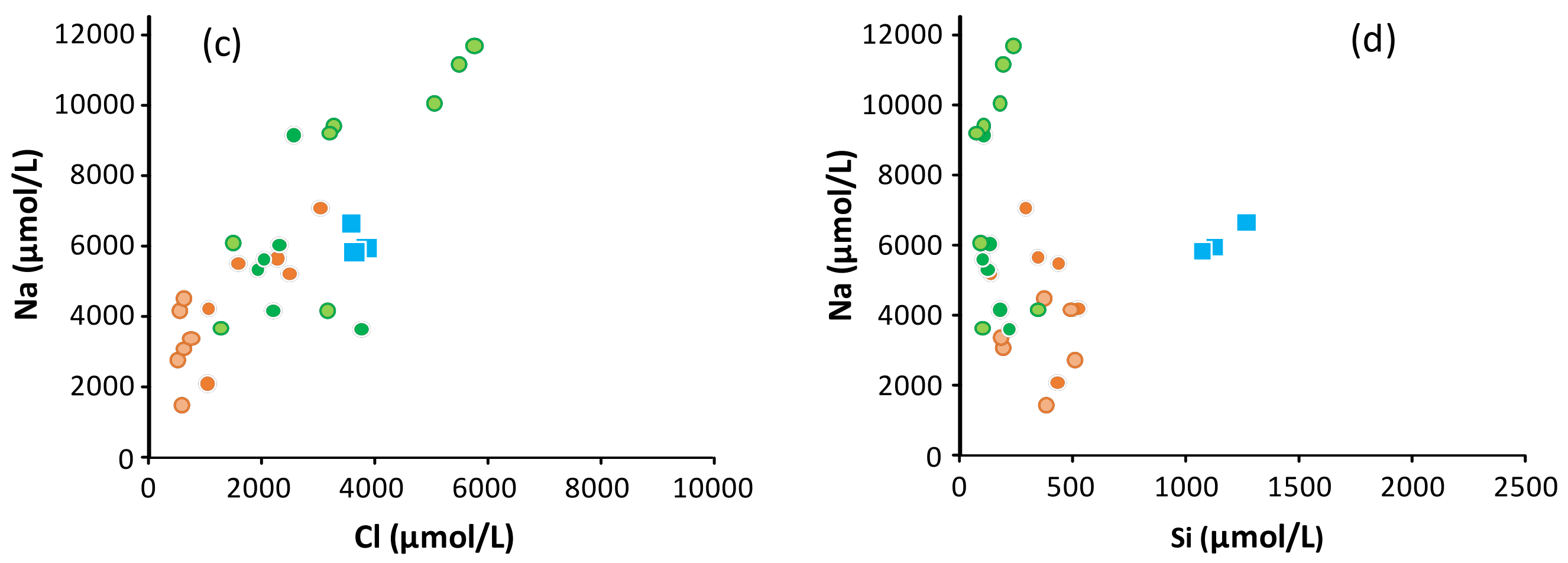
Figure 3
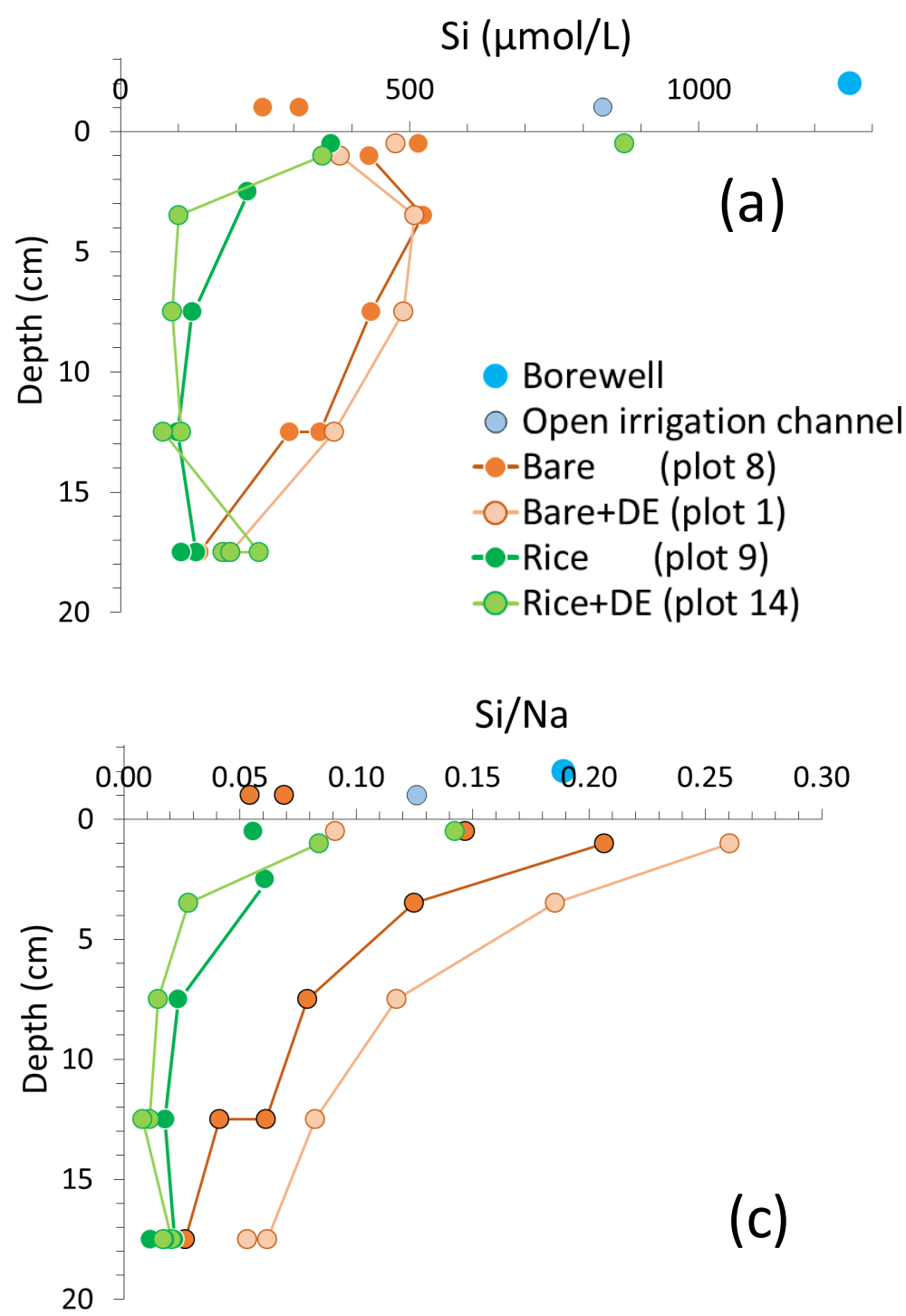
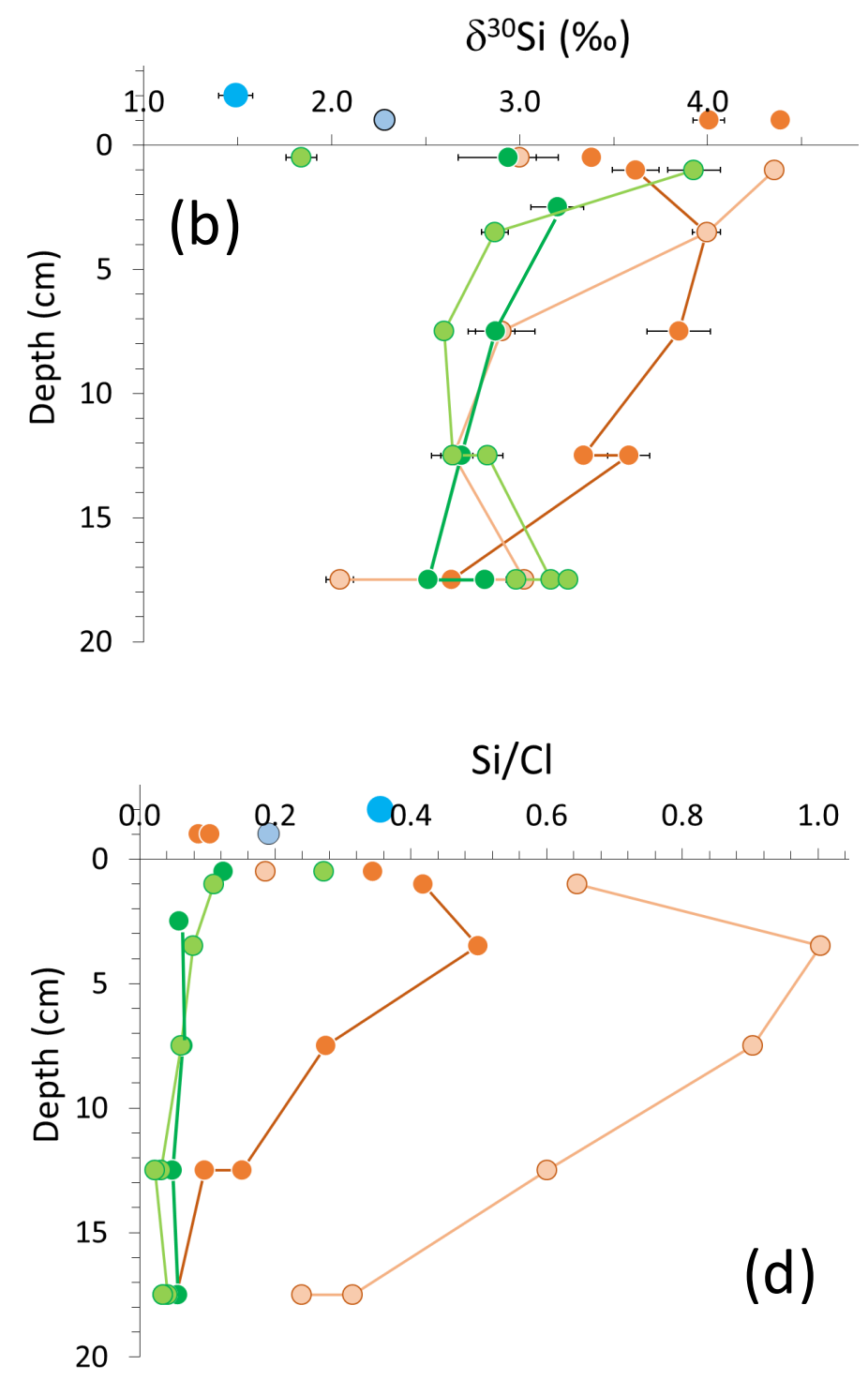
Figure 4

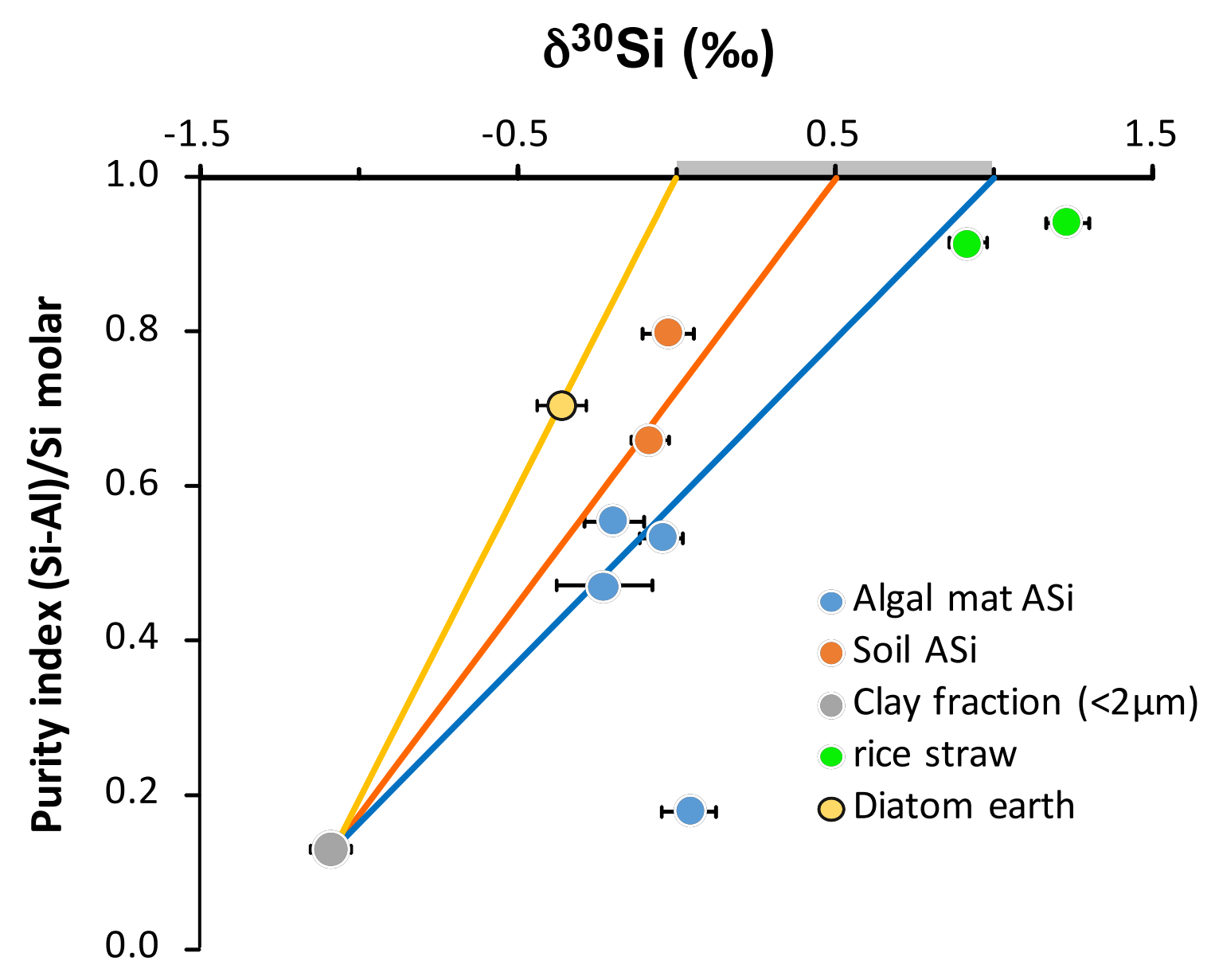


Figure 5
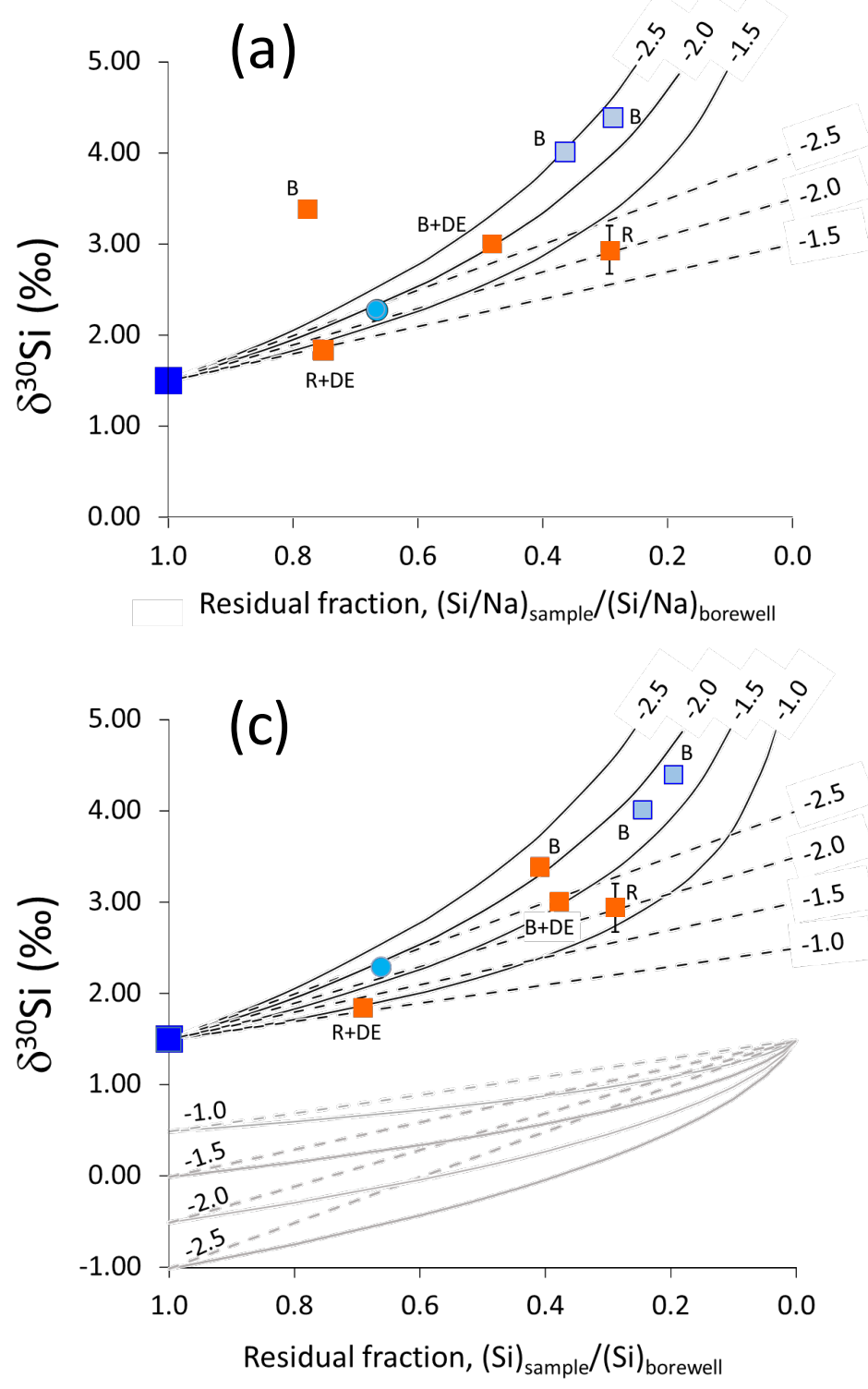

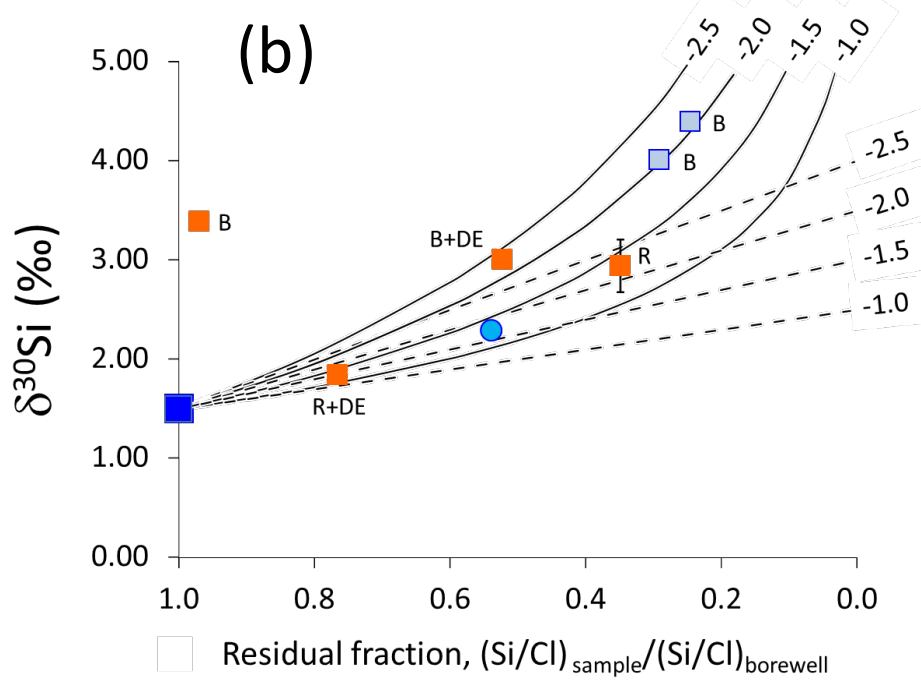

- Rayleigh, source

_ Rayleigh, cumulative product

- - Steady state, source

- - Steady state, cumulative product

Borewell

Open channel

$\square$ Stagnantwater

Rhizon $1 \mathrm{~cm}$ 
Figure 6

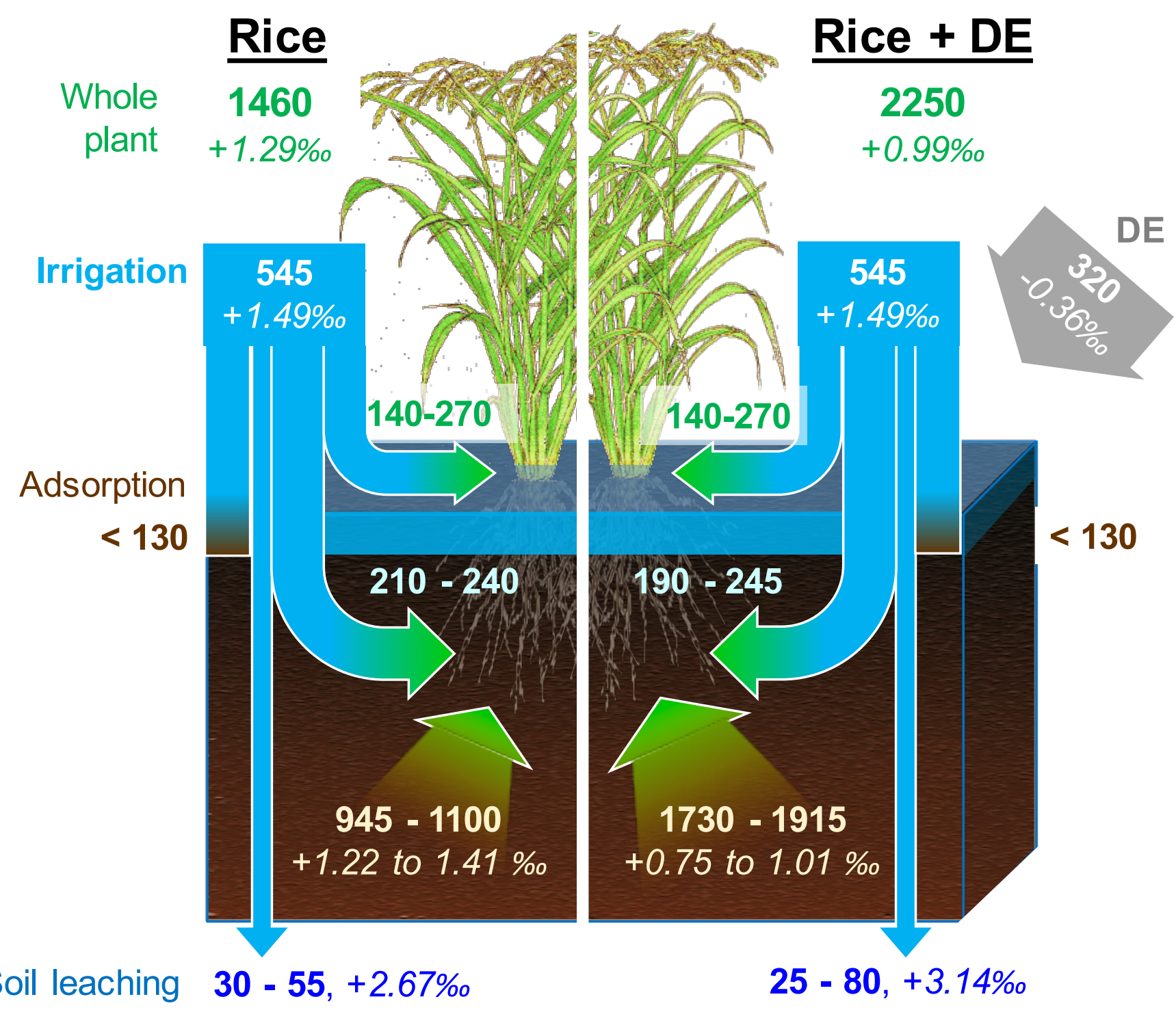


Figure 6 = schema synthetique avec flux possibles

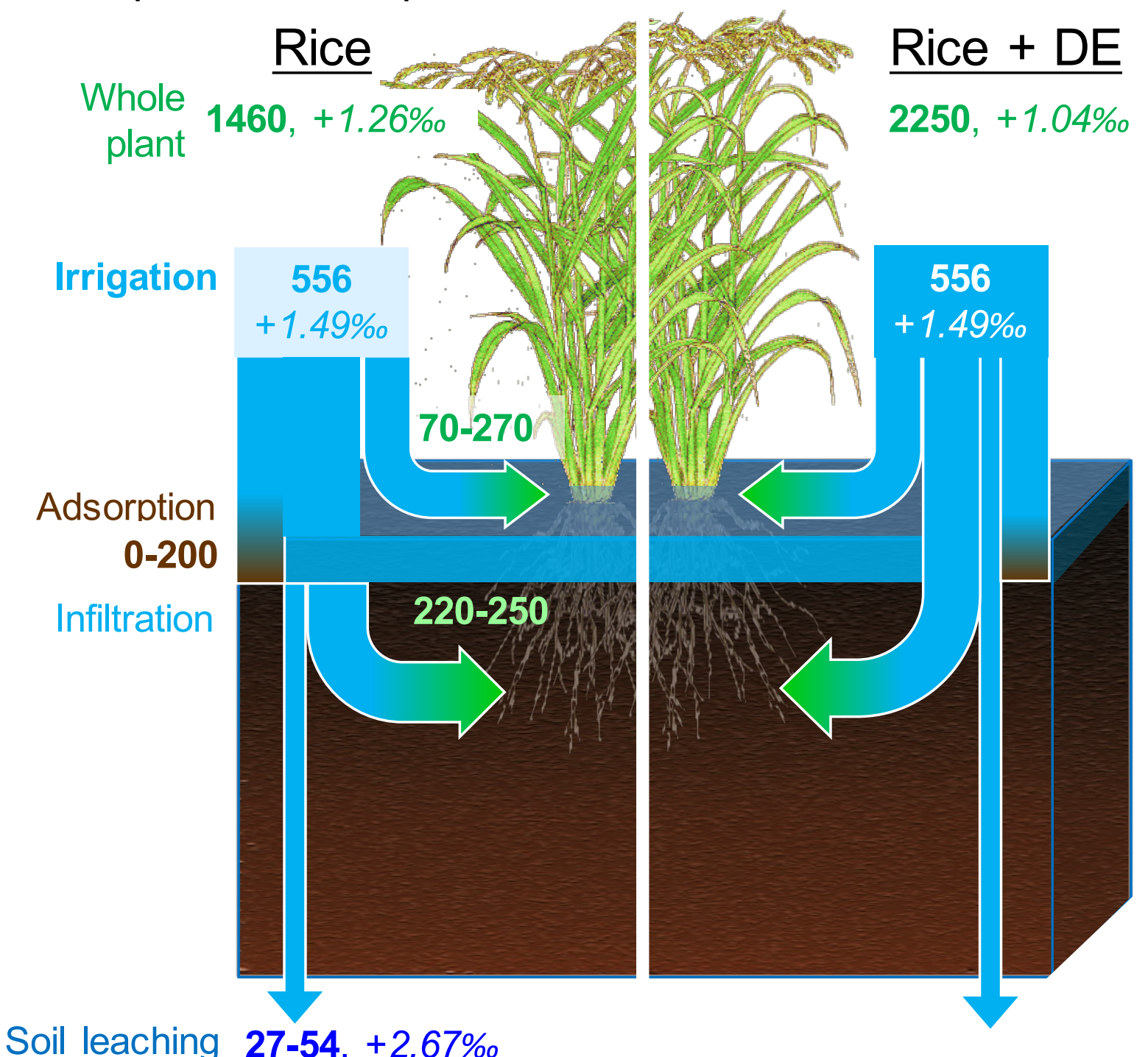


Figure 6 = schema synthetique avec flux possibles

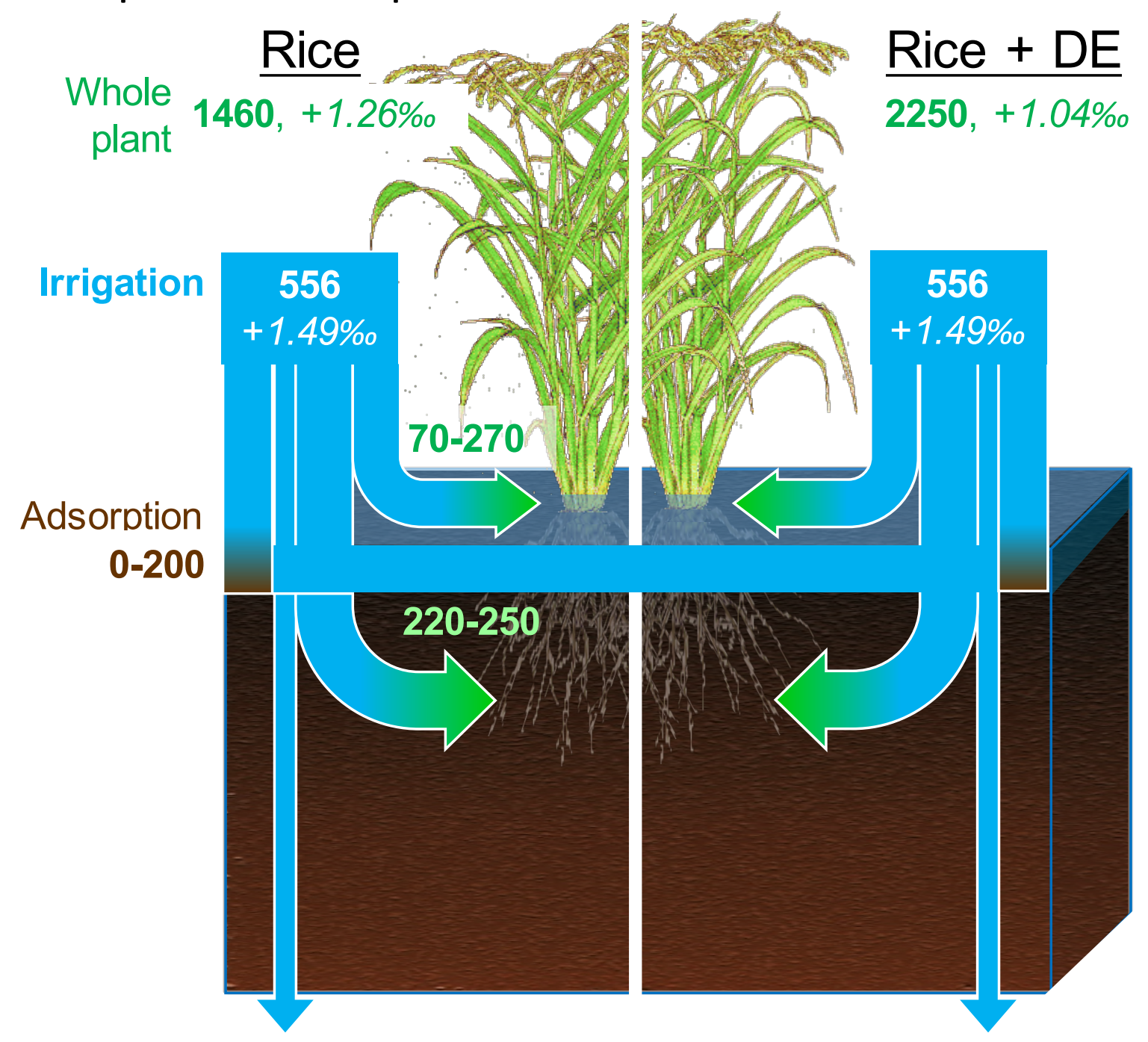

Soil leaching $\mathbf{2 7 - 5 4},+2.67 \%$ o 
Figure 6 = schema synthetique avec flux possibles

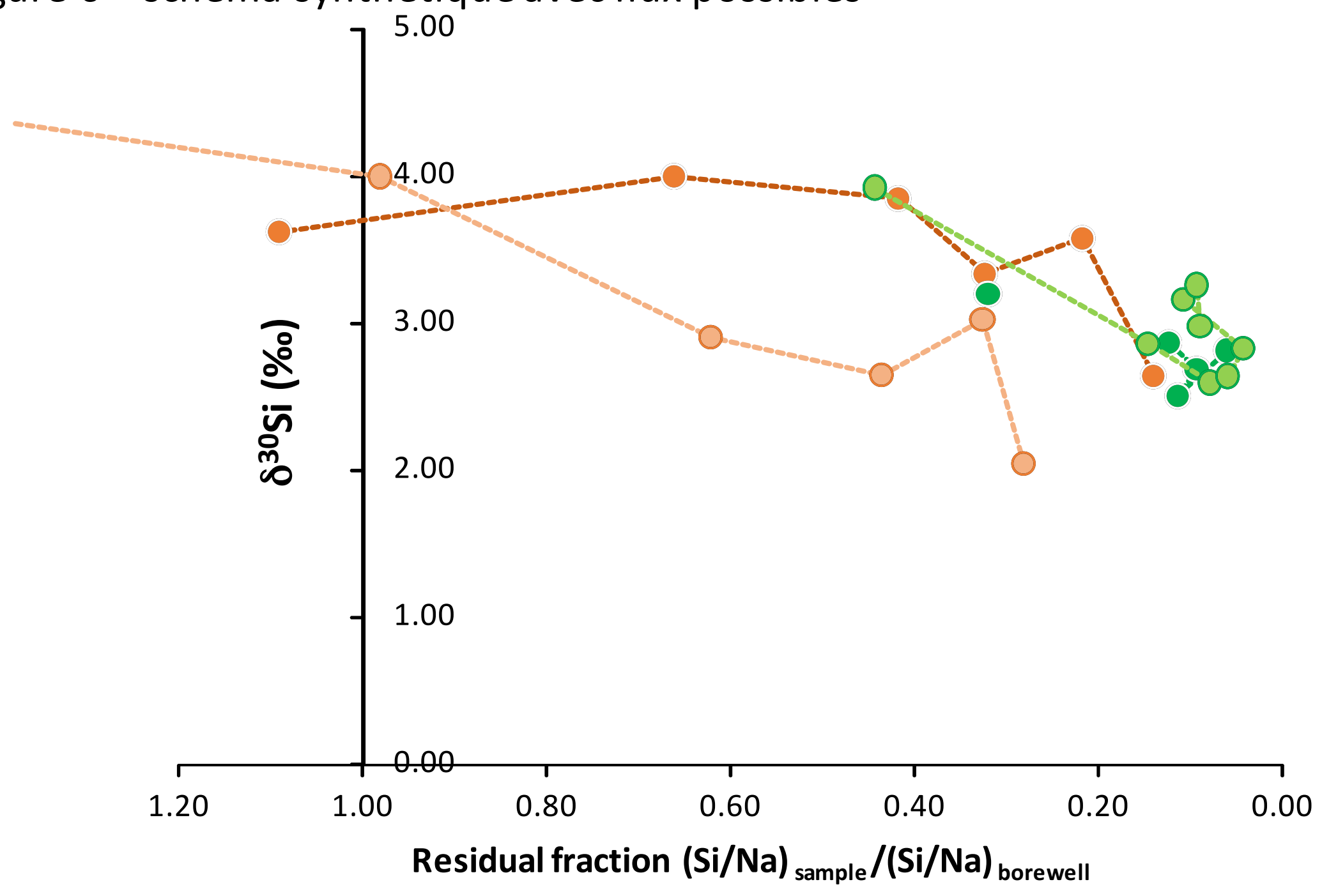




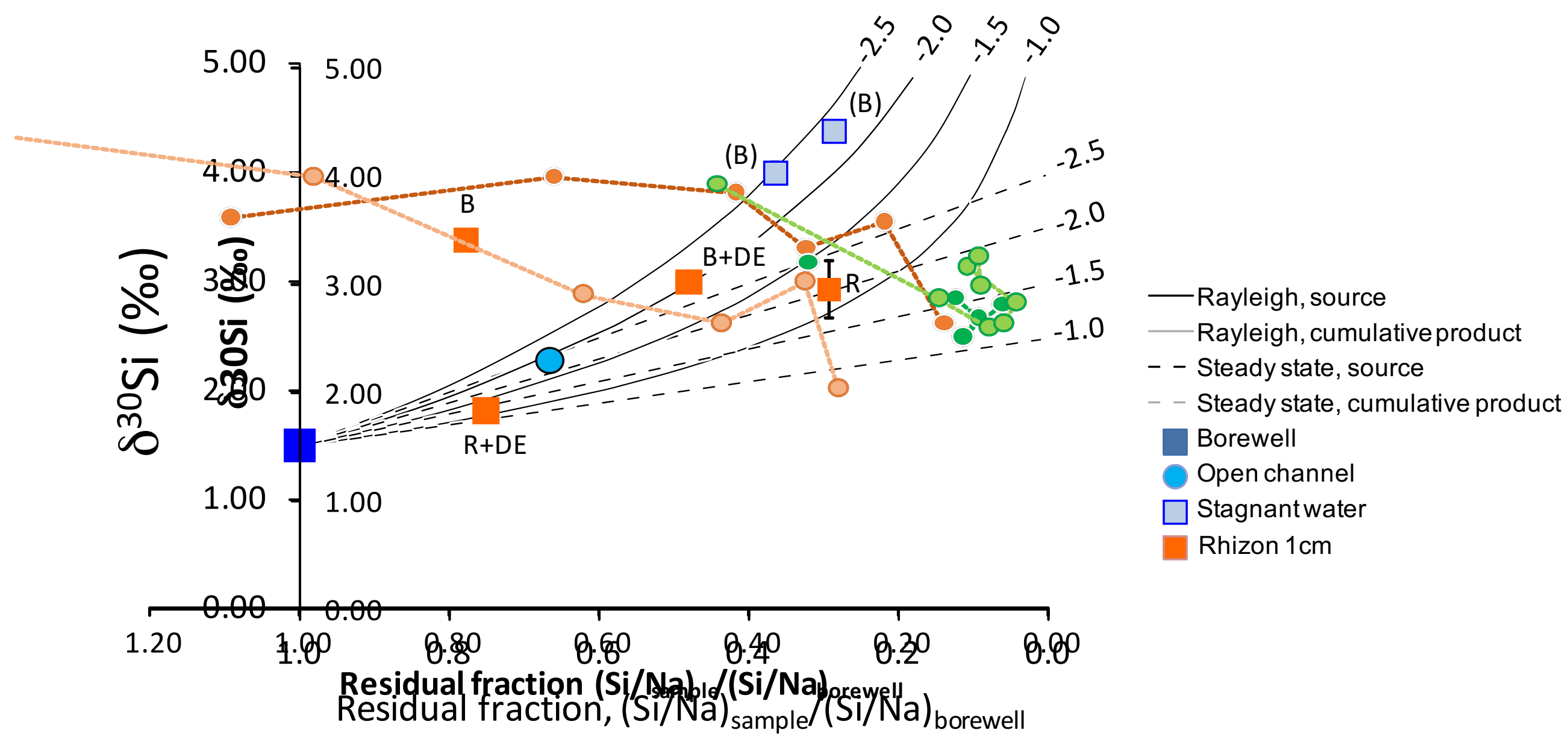




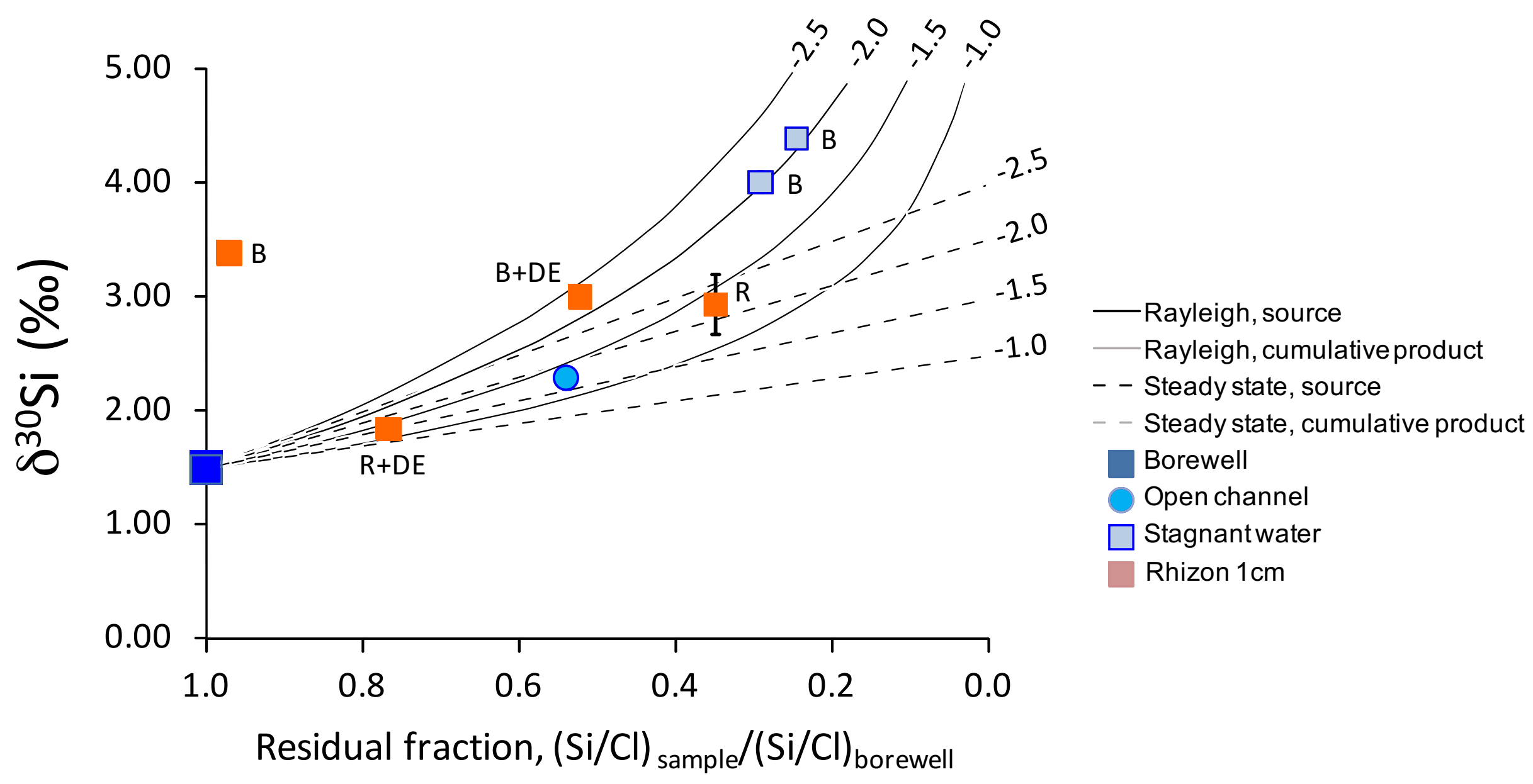




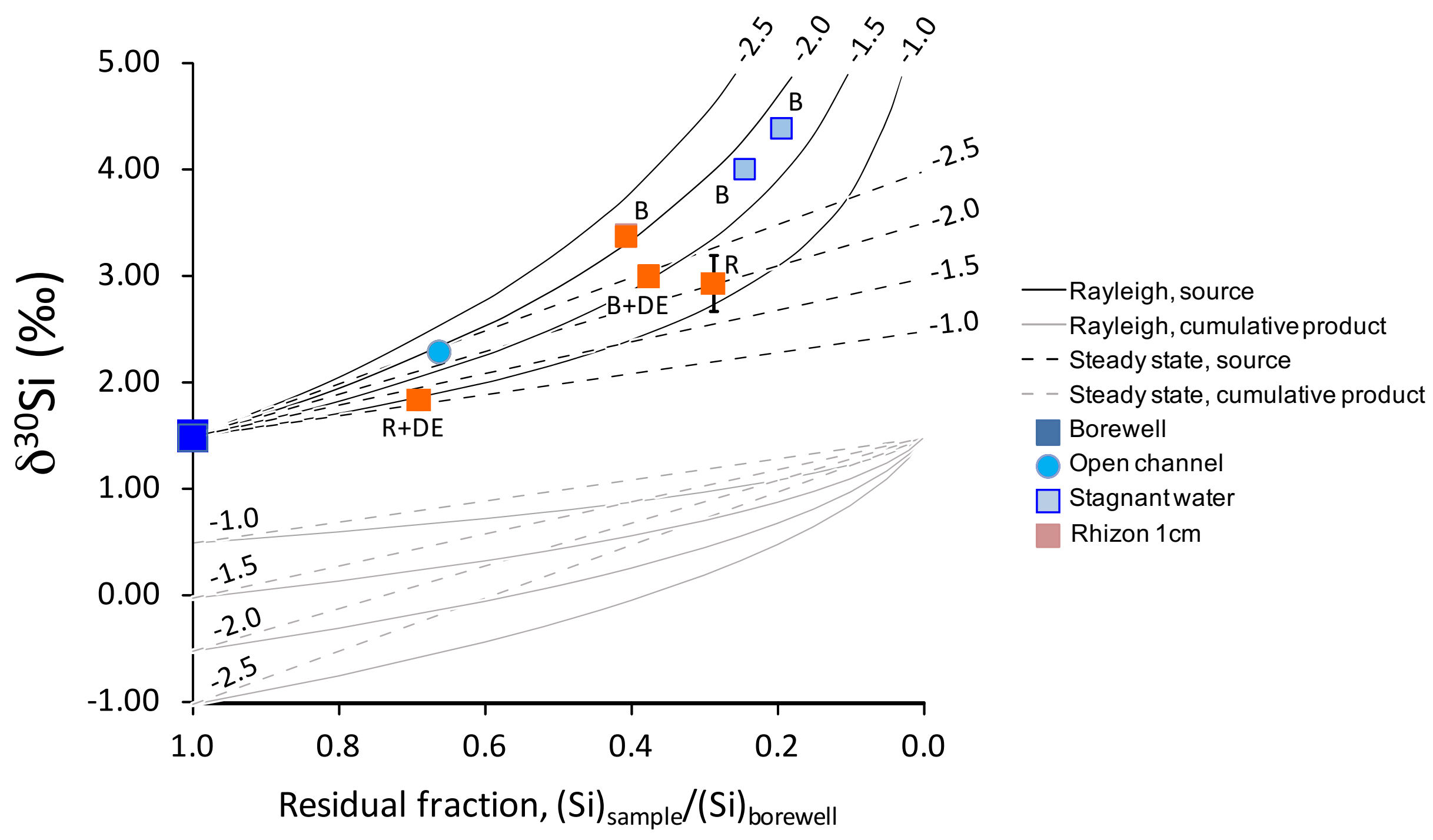




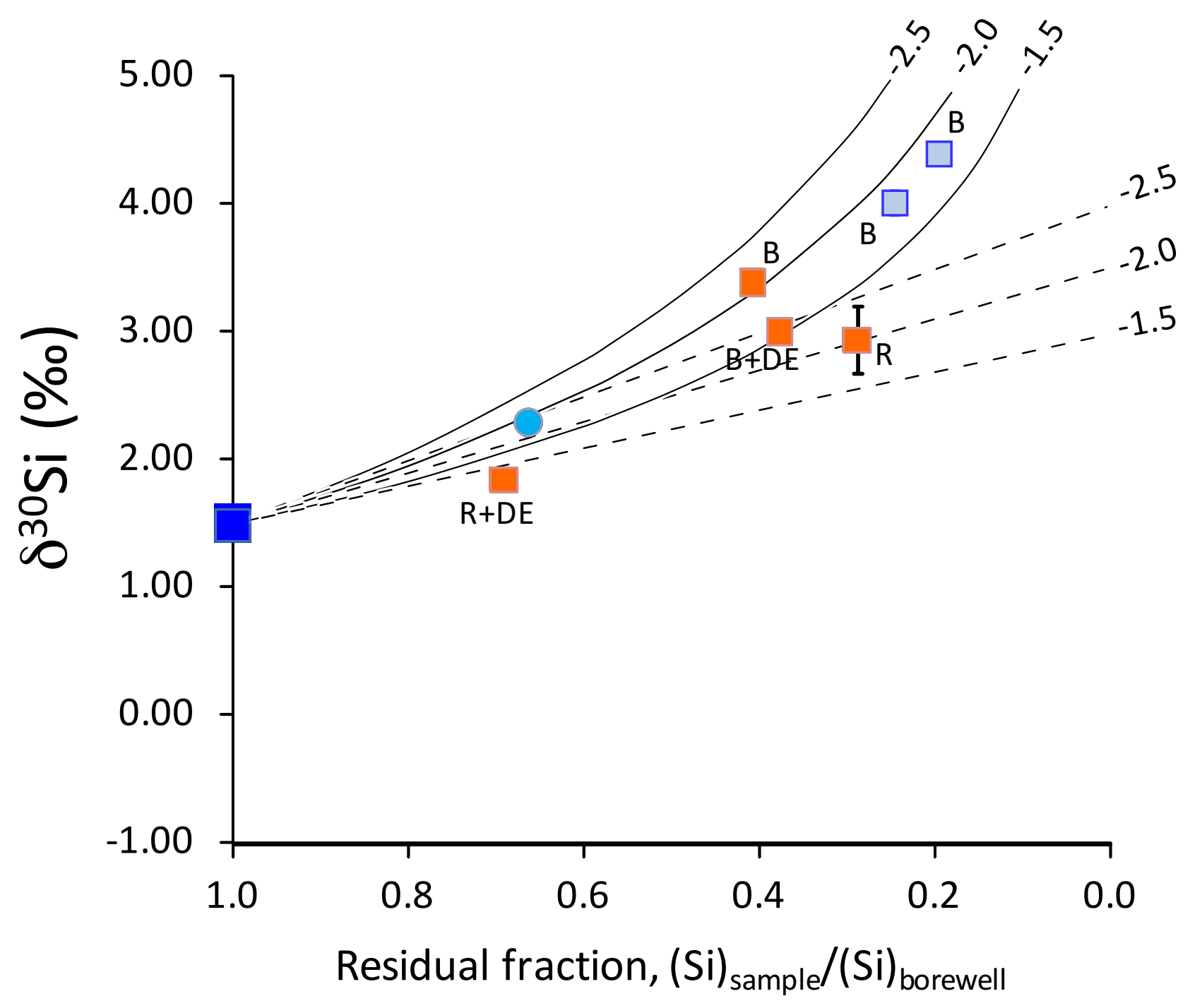




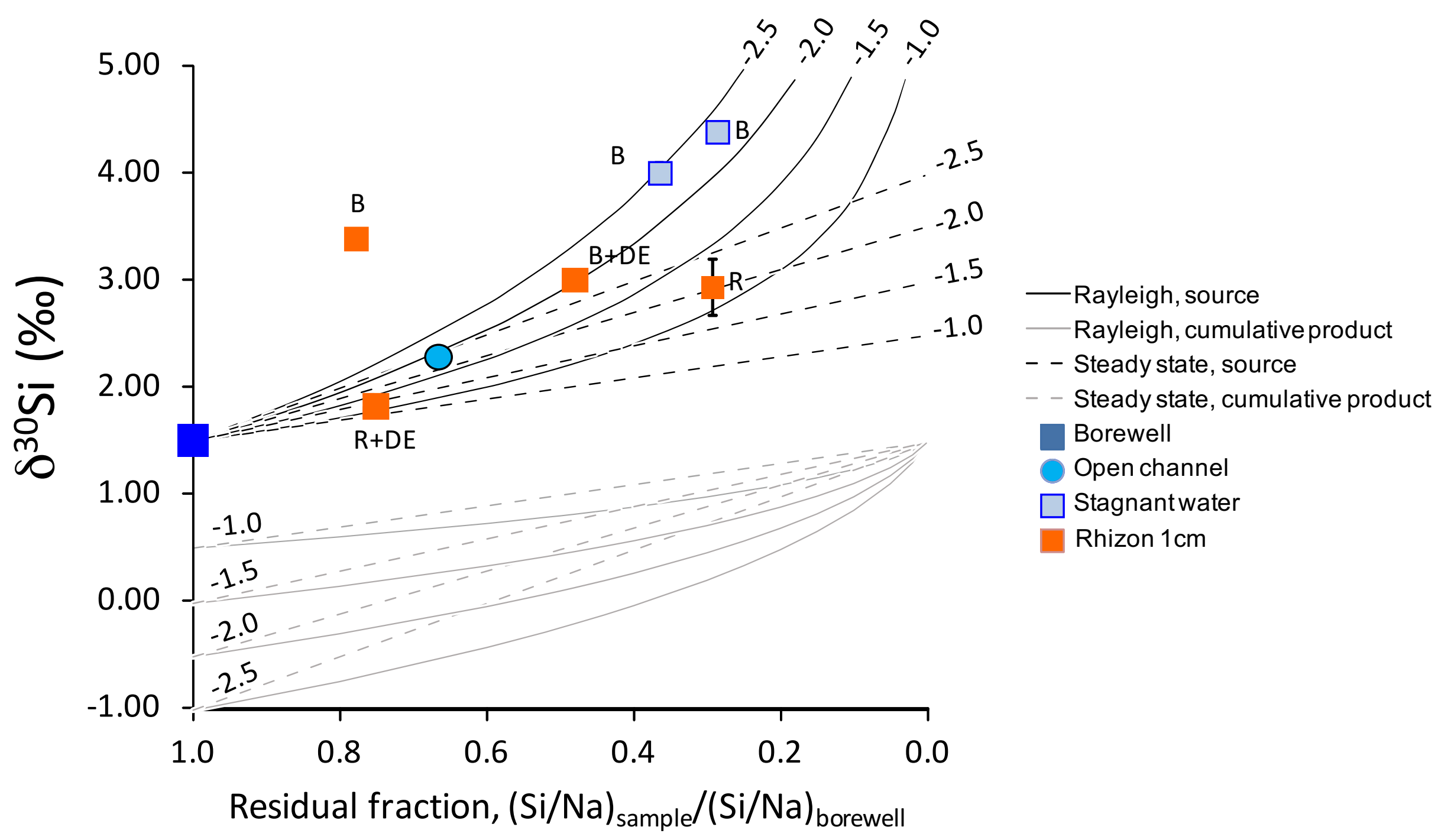




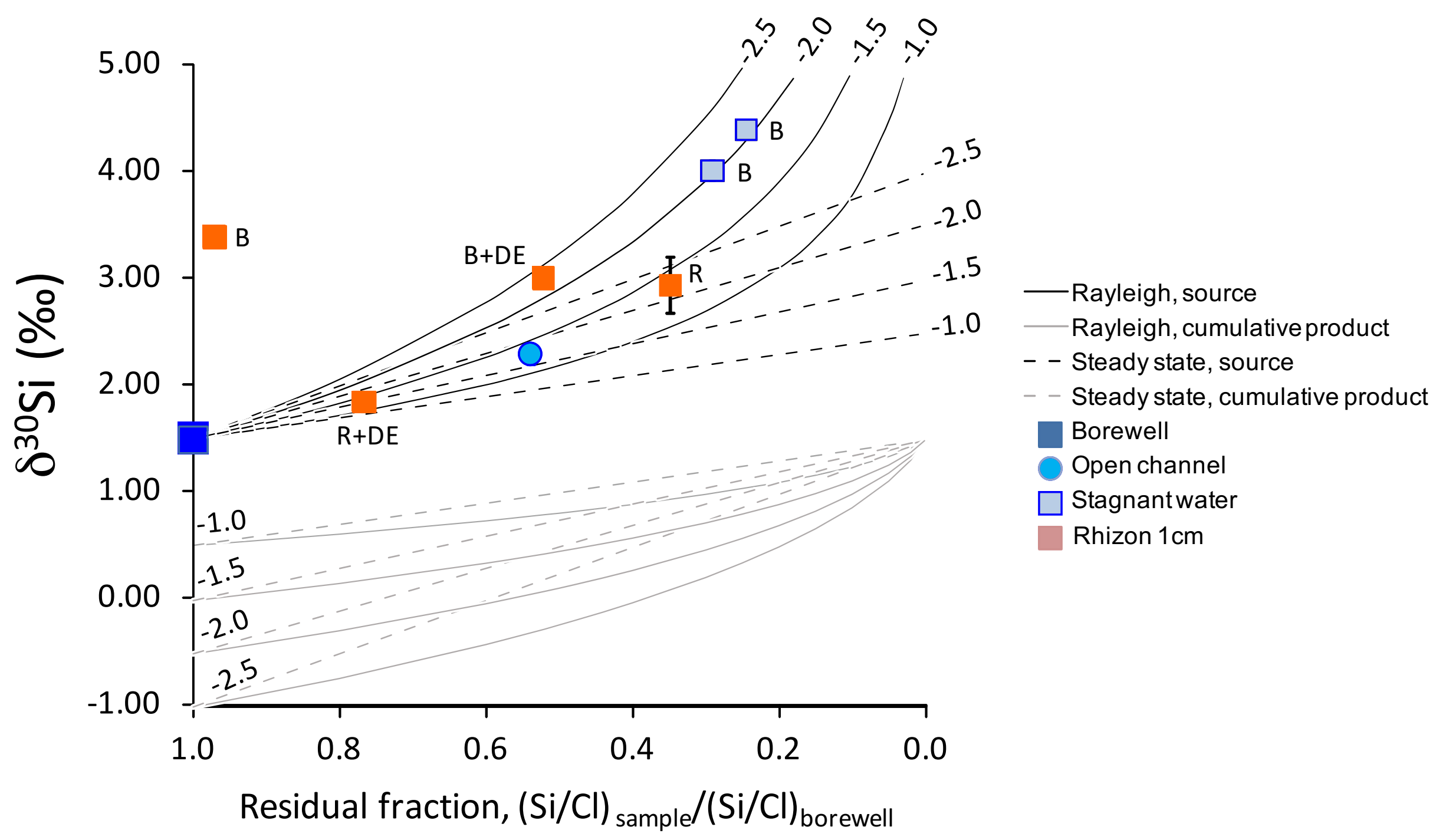




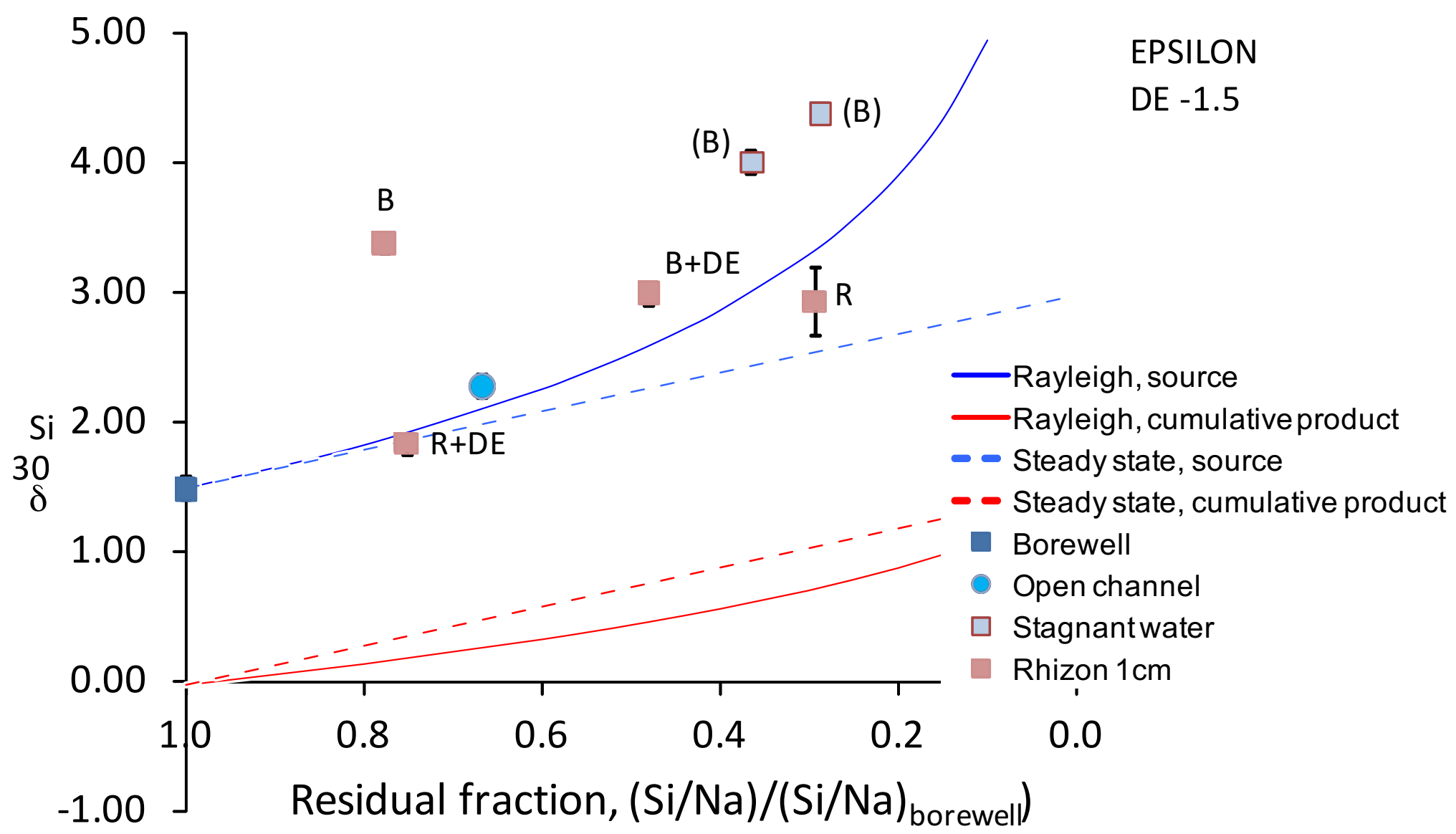




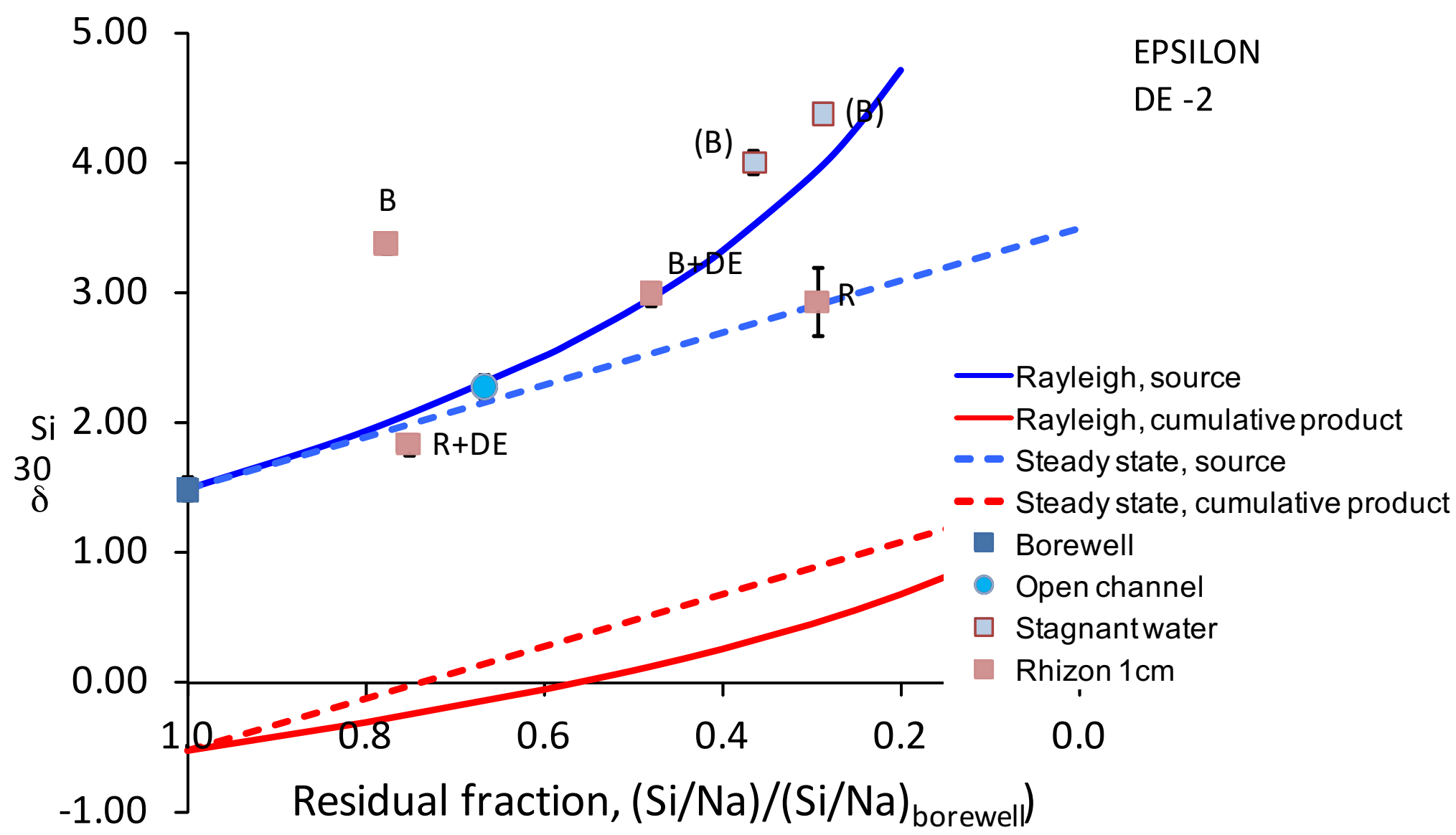




\subsection{0}

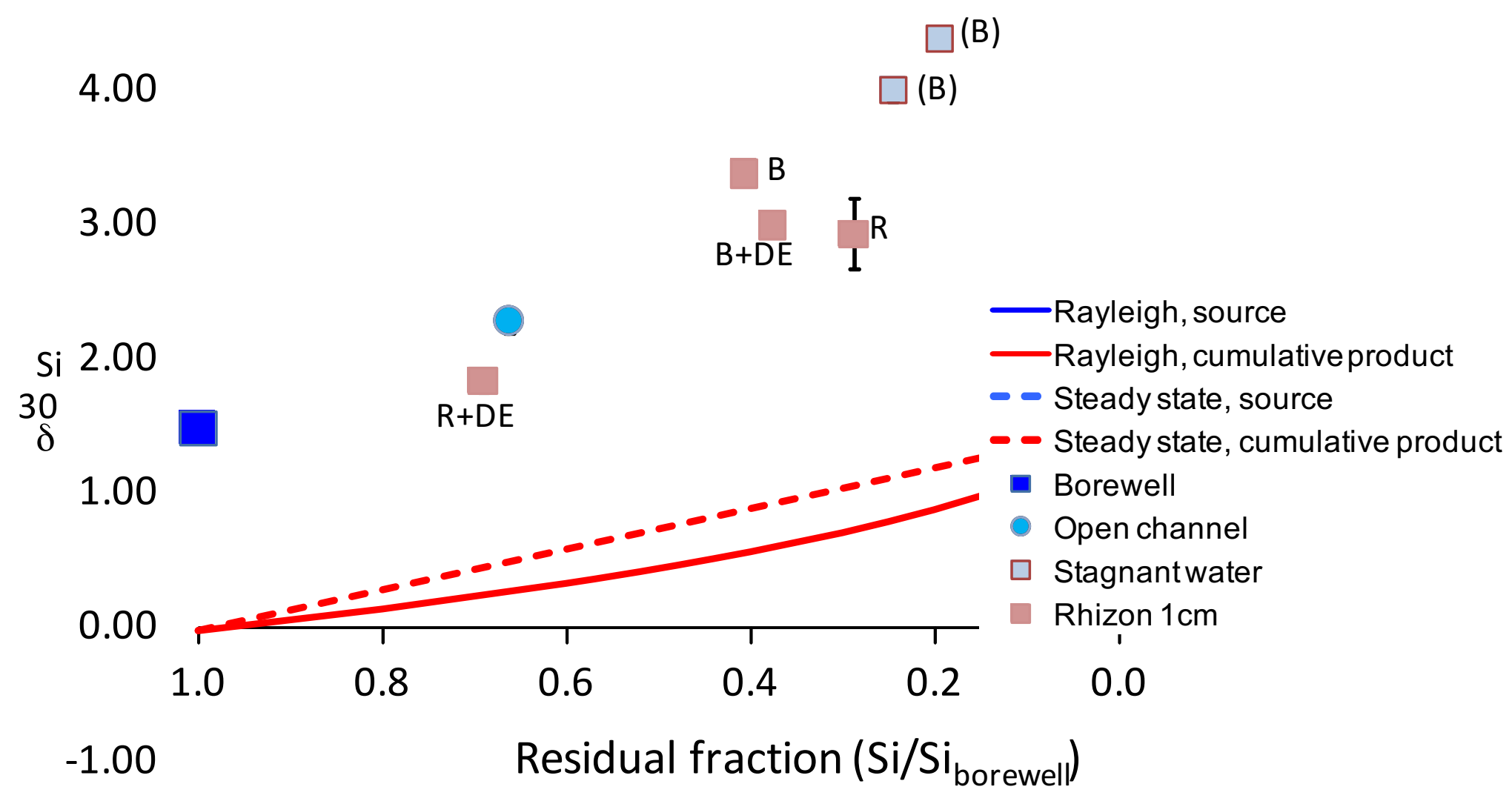




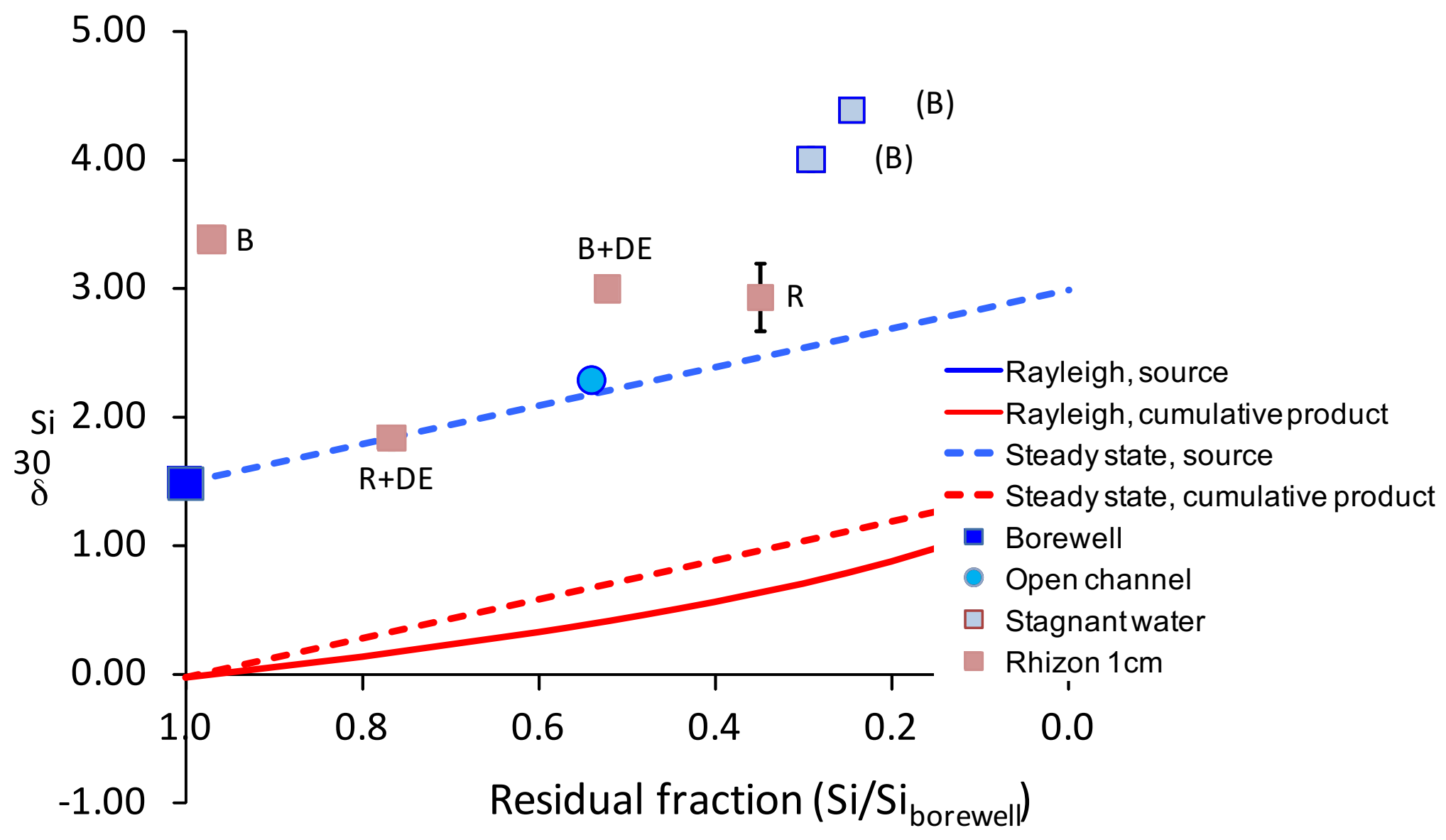




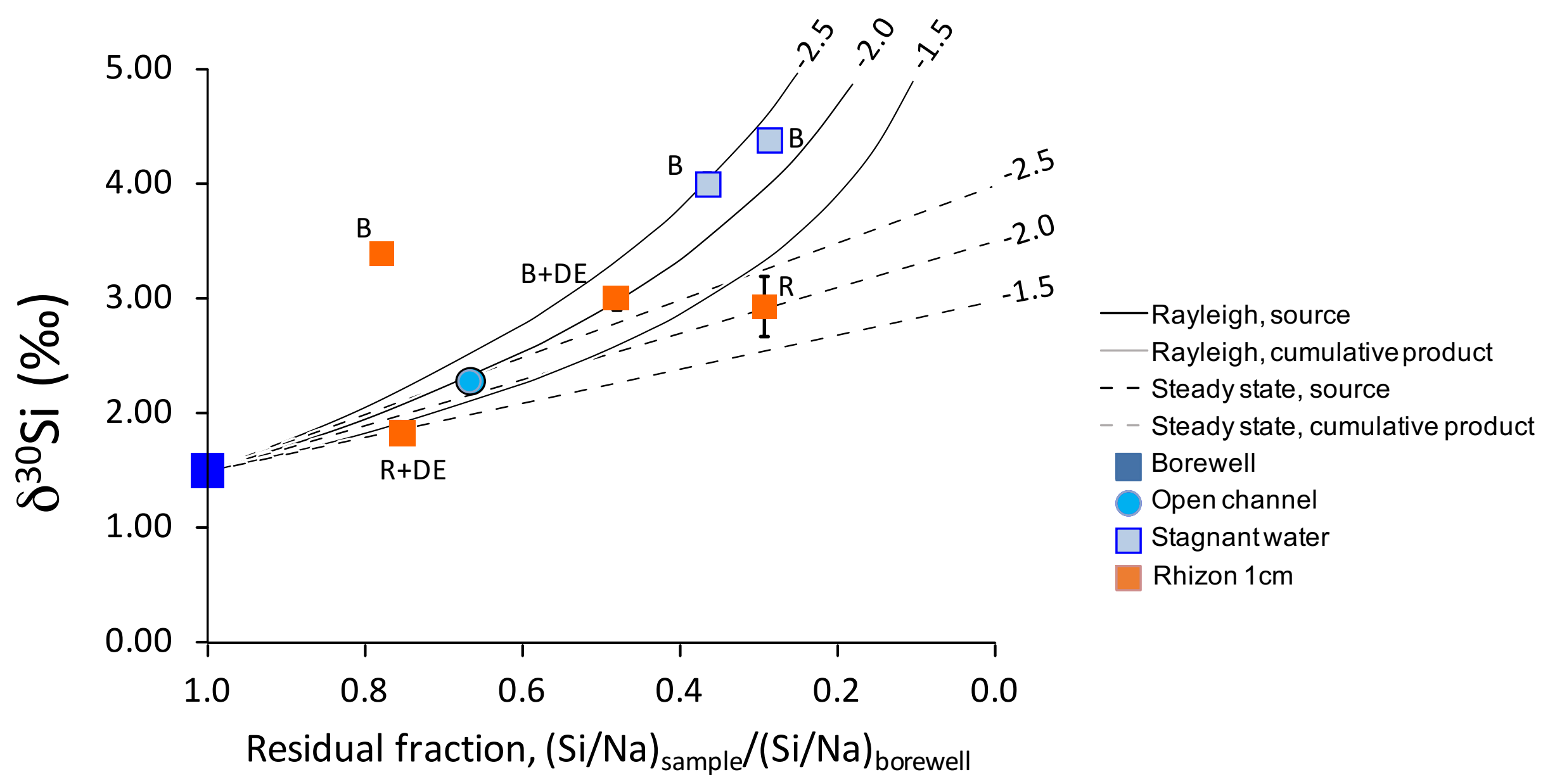




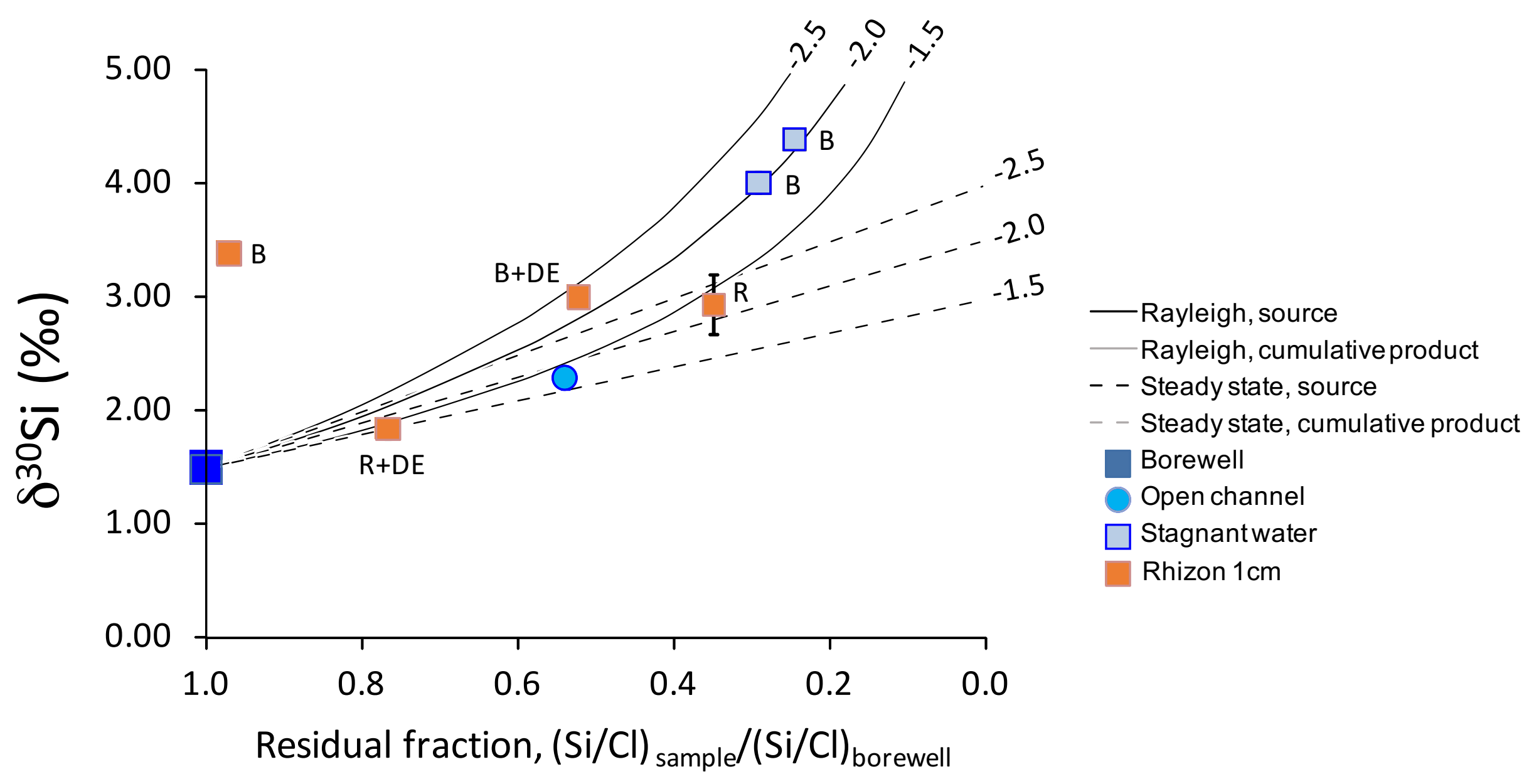




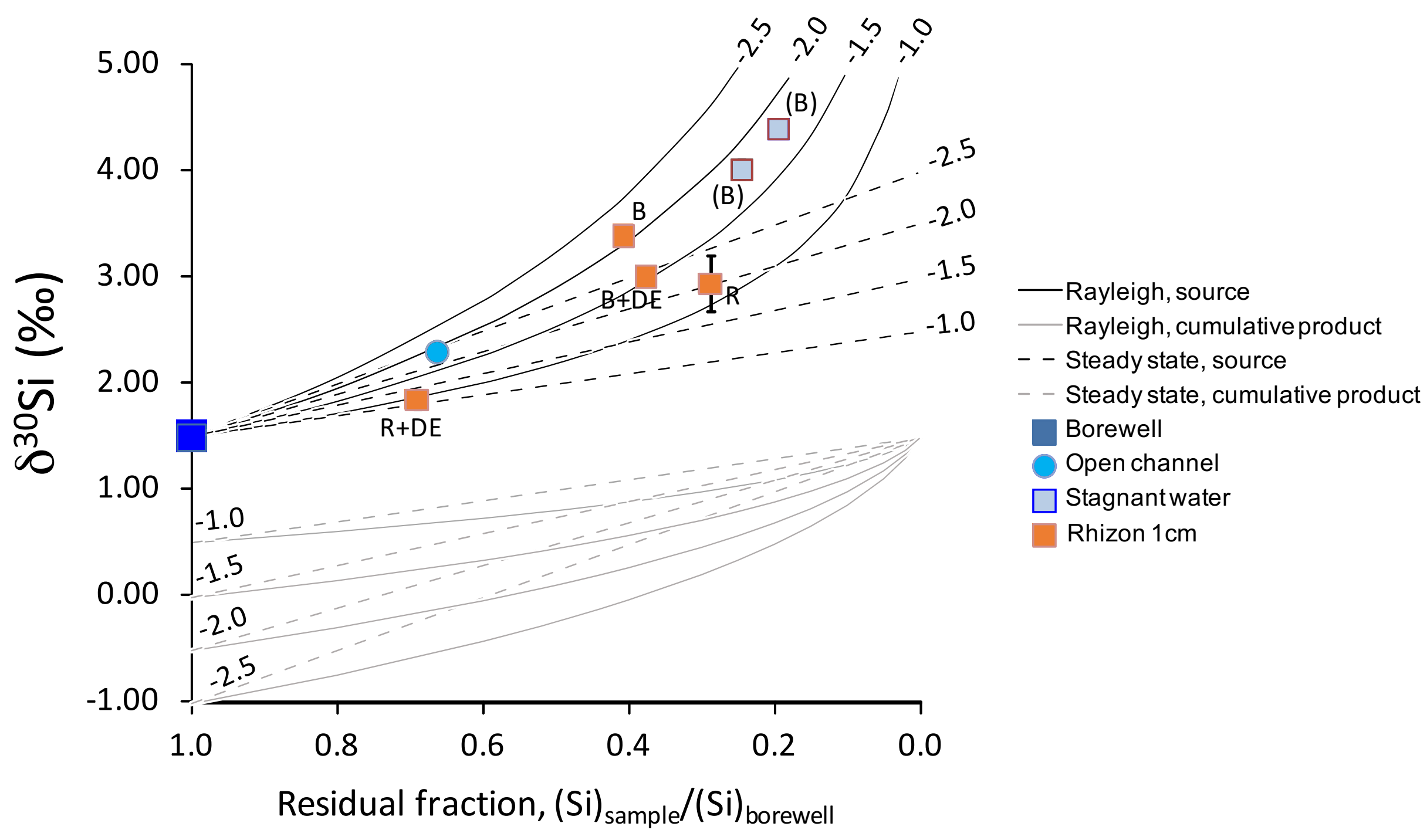




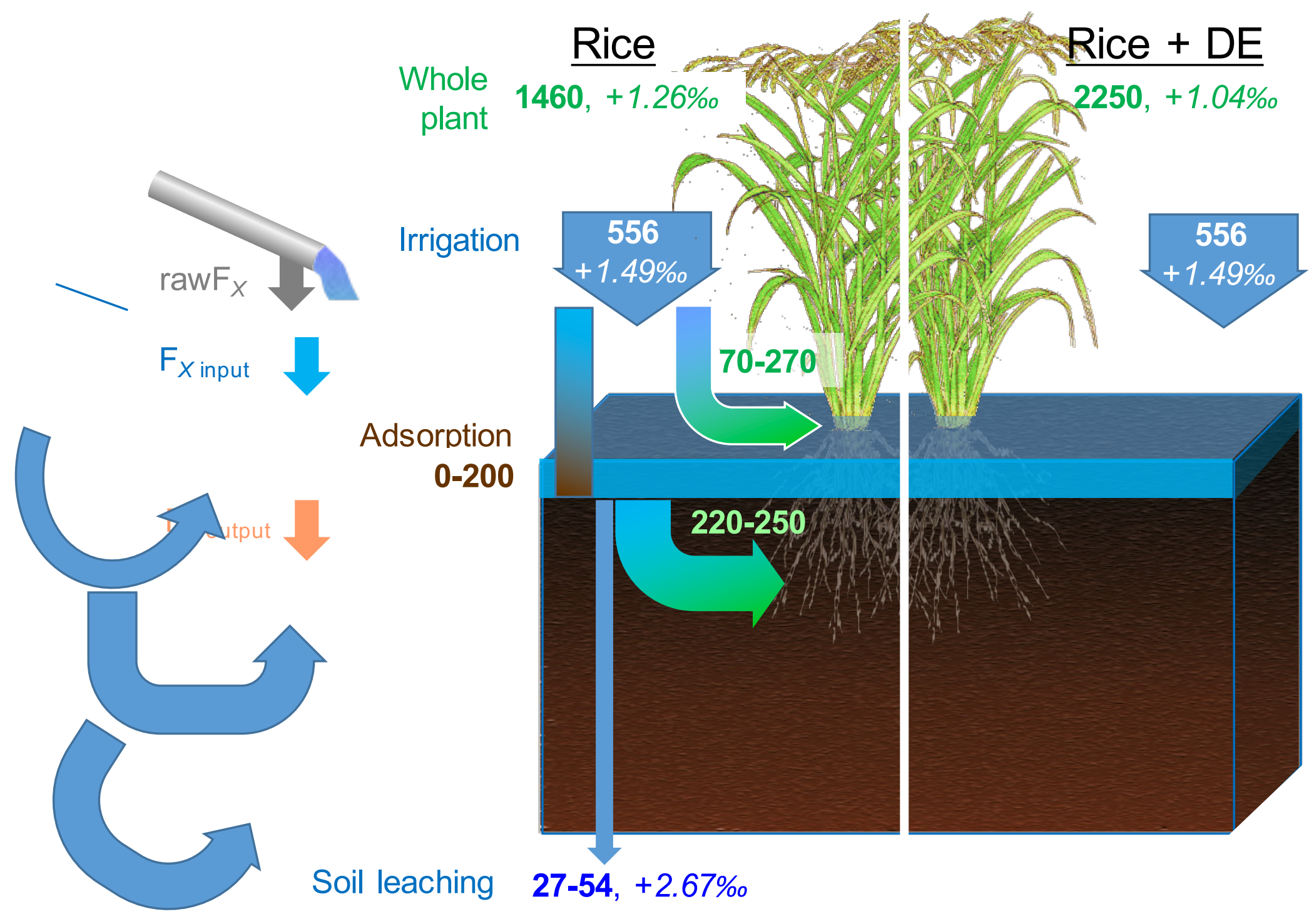



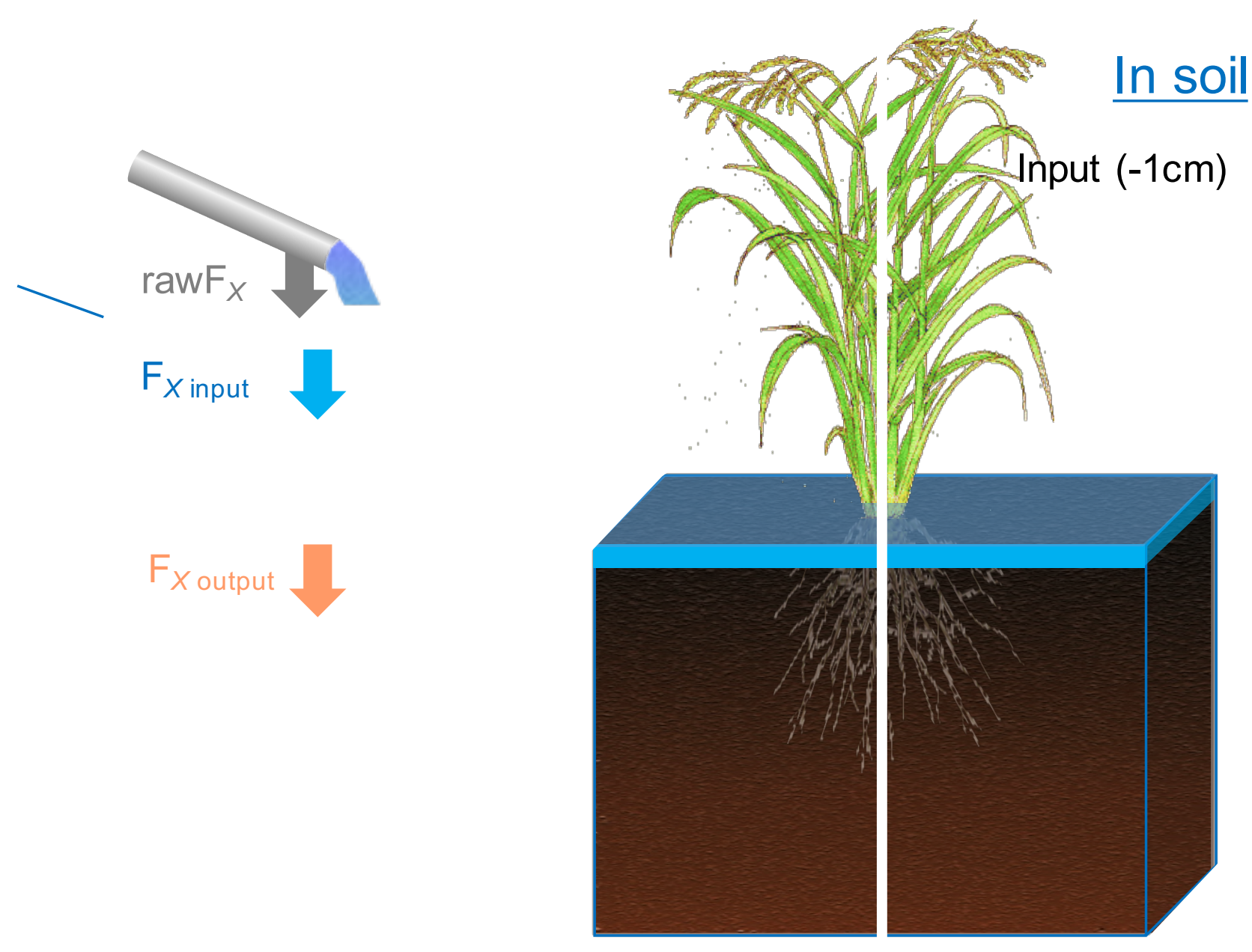


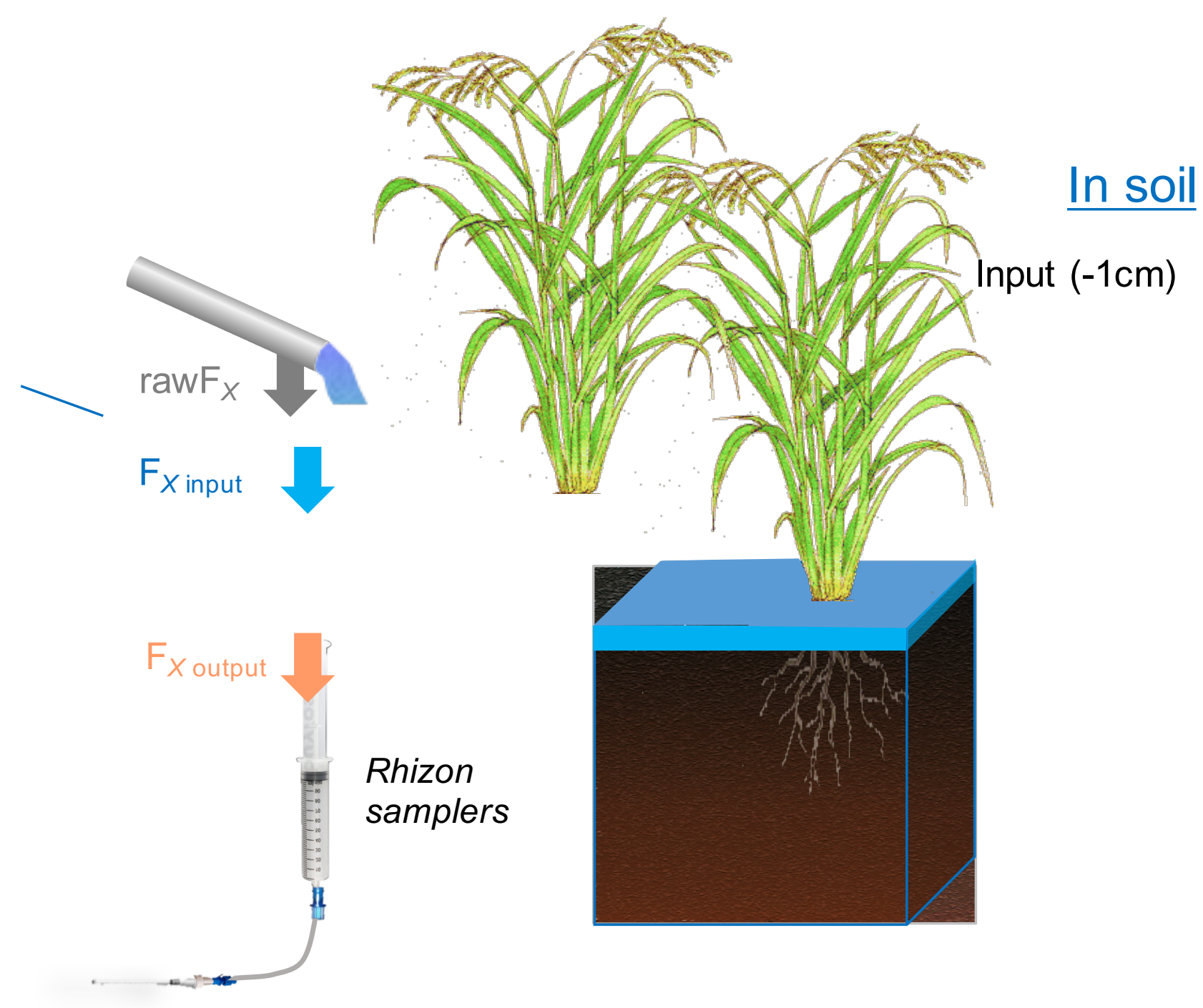


34 isotopic fractionation factor $\left({ }^{30} \varepsilon\right)$ between bore well and stagnant water compositions is close to $-1 \%$, i.e. the isotopic fractionation factor known for rice, indicating that above-ground DSi removal would be dominated by plant uptake upon adsorption. Within the soil layer, pore water DSi decreases much faster in rice experiments than in bare ones, demonstrating the efficiency of DSi rice uptake upon adsorption.

Total irrigation-DSi to plant-Si would then represent 24 to $36 \%$ in rice experiments (over $1460 \pm 270 \mathrm{mmol} \mathrm{Si} \mathrm{m}^{-2}$ in biomass) and 15 to $23 \%$ in rice+DE ones (over $2250 \pm 180$ mmol Si $\mathrm{m}^{-2}$ ). The $\delta^{30} \mathrm{Si}$ signature of whole plants was significantly different in the rice+DE plot analyzed, $0.99 \pm 0.07 \%$, than in the rice one, $1.29 \pm 0.07 \%$. According to these $\delta^{30} \mathrm{Si}$ signatures, the main $\mathrm{Si}$ source from the soil would be the amorphous silica pool (ASi). A slight contribution of $\mathrm{DE}$ to the rice plant could be detected from the Si isotopic signature of rice.

\section{Conclusions}

The $\delta^{30} \mathrm{Si}$ signatures of the various soil-plant compartments, when associated to $\mathrm{Si}$ mass balance at scale, constitute a reliable proxy of the $\mathrm{Si}$ behavior in paddy fields. The solute $\mathrm{Si}$ balance is controlled by rice uptake in rice plots and by adsorption and diatom uptake in bare ones. The main Si sources for the rice plants were soil ASi, irrigation Si and to a lesser extent Si fertilizer when it was applied.

Introduction

There is an increasing body of evidences showing that $\mathrm{Si}$ is playing a beneficial role for the development of crops (Guntzer et al., 2012; Liang et al., 2015). The Si concentration in plants depends primarily on the concentration of silicic acid in the soil solution (Ding et al. 2005; Henriet et al., 2008) and is not correlated to the total Si concentration of the soil (Brenchley and Maskell, 1927). However, correlations were observed between the Si concentration in rice and the percentage of clay in soils (Cheng, 1982), and between the Si concentration in rice or banana and the stock of weatherable minerals (Henriet et al., 2008; Makabe et al., 2009) but the contribution of the potential Si sources remain to be quantified. The geochemical cycle of $\mathrm{Si}$ in natural ecosystems such as forest and grassland is first controlled by silicate rock weathering which constitutes the primary source to hydro and ecosystems. Depending on weathering intensity, Si can be partitioned between a dissolved phase (DSi) and secondary clay minerals such as smectite (bisilialitisation, i.e. slight weathering) or kaolinite 
extreme weathering (allitisation) (e.g. Allen, 1997). The dissolved silica taken up by plants precipitates as amorphous silica (ASi) particles called phytoliths (Piperno 1988; Meunier et al., 2017). Because of its higher rate of dissolution in soil solution (Fraysse et al., 2009) Si from phytoliths can be preferentially recycled by plants (Alexandre et al. 1997; Lucas, 2001) or leached out of the soils and control the flux delivered to oceans by rivers as DSi and ASi (Derry et al., 2005; Riotte et al., 2014; Cary et al., 2005; Hughes et al., 2011; Frings et al., 2014).

The biogeochemical cycle of $\mathrm{Si}$ in cultivated land is poorly documented. According to Vandevenne et al. (2012) agriculture may have disturbed the natural cycle of Si because plant materials do not return to the field and are injected into the urban cycle. Several perturbations have been documented in the surface soil horizons: depletion of the phytolith pool (Struyf et al., 2010; Clymans et al., 2011; Guntzer et al., 2012; Vandevenne et al., 2015a) and a decrease of crystallinity of clays (Irfan et al., 2017). Besides, repeated crop removal can reduce the concentration of potentially available Si to the extent that Si fertilization is necessary (Datnoff and Rodrigues, 2005; Meunier et al., 2008; Savant et al., 1997). Desplanques et al. (2006) showed in a rice field of Camargue (France) that if soil ASi would be the only source of Si for plants, this stock would be exhausted after five years of cultivation. Another potential cause of Si-depletion in rice cropping systems is DSi leaching from the soil. According to the estimation made by Nguyen et al, (2016) from an hydrological modelling in Viet-Nam, the potential loss could reach 10 tons $\mathrm{Si} \mathrm{ha}^{-1} \mathrm{yr}^{-1}\left(350.10^{3} \mathrm{~mol} \mathrm{Si} \mathrm{ha}^{-1} \mathrm{yr}^{-1}\right)$, i.e. ten times the Si taken up by rice plants in this system. Therefore, there is a need for better documenting the $\mathrm{Si}$ budget in the cultivated land. In a recent rice cropping experiment in California where straw was incorporated into the soil prior to cultivation, Seyffert et al. (2013) monitored the Ge/Si ratio in soil pore water and observed an increase of $\mathrm{Ge} / \mathrm{Si}$ during the fallow season and a decrease during the cropping season. These authors assigned these relative variations to the $\mathrm{Si}$ release from the straw and its further uptake by the rice crop. Improving the quantification of Si-fertilizer's contribution for adjusting the doses applied to the plant requirements would require not only a thorough Si mass balance in paddy fields (quantifying the Si sources and sinks of Si, including Si-fertilizers contribution), but also a proxy of Si sources.

Studying the silicon isotopic compositions of the various soil-water-plant compartments of rice cropping experiments could bring new insight for the Si mass balance at soil-plant scale and particularly about the nature of the Si sources to the rice. Silicon has three natural (stable) isotopes, ${ }^{28} \mathrm{Si},{ }^{29} \mathrm{Si},{ }^{30} \mathrm{Si}$ which fractionate during water-soil interactions and plant uptake 
101 (reviews in Opfergelt et al., 2012; Frings et al., 2016). The partition of Si between dissolved 102 load and clay minerals during silicate weathering induces preferential allocation of the light Si isotopes in clay minerals and subsequent enrichment of heavy $\mathrm{Si}$ isotopes in the solution

104 (Ziegler et al., 2005; Georg et al., 2007). As a consequence, primary bedrock silicates, 105 secondary clay minerals and soil pore water often exhibit distinct isotopic signatures. 106 Similarly, Si adsorption onto ferrihydrite or goethite favors light isotopes (Delstanche et al., 107 2009) according to an isotopic fractionation factor $\left({ }^{30} \varepsilon\right)$ varying between $-1.1 \%$ for 108 ferrihydrite to $-1.6 \%$ for goethite. Such isotopic fractionation also occur between plant and 109 solution. The first studies of the Si isotopic signatures in rice plants highlighted ${ }^{30} \varepsilon$ between 110 the soil or the hydroponic solution and the rice plants of $-1 \%$ (Ding et al., 2008), a value 111 similar to the few other plants measured up to now: banana, wheat or bamboo (Opfergelt et 112 al., 2012 and references therein). Recently, hydroponic experiments (Sun et al., 2016) 113 revealed that the $\mathrm{Si}$ isotopic fractionation factor between the external solution and the whole 114 plant could indeed range from $-0.4 \%$ to $-1.13 \%$ according to the DSi concentration of the 115 solution (here 0.17 to $8.5 \mathrm{mmol} \mathrm{Si} \mathrm{L}^{-1}$ ). Sun et al. deduce from these experiments that the rice 116 plant takes up most of the silica through an active mechanism and that the preferential uptake 117 of light $\mathrm{Si}$ isotopes occurs via a passive mechanism. The respective $\delta^{30} \mathrm{Si}$ signatures of rice 118 and feeding solution are then expected to clarify the Si accumulation processes in the plant. 119 To our knowledge, the only study which reported $\mathrm{Si}$ isotopes on cultivated soils solution 120 showed a shift to heavier values, attributed to a decrease of the phytolith source for DSi 121 (Vandevenne et al., 2015b).

122 The objective of this study is to perform a rice cropping experiment for identifying and 123 assessing the contributions of the various Si sources to the plant and the possible contribution 124 of a Si-fertilizer, diatomaceous earth (DE). DE have proven to be a good fertilizer in India as 125 measured by the increased Si concentration in the shoots and the grain yield (Crooks and 126 Prentice, 2016; Pati et al., 2016). Indeed, DE contains relics of diatom tests that are made of 127 amorphous silica. Amorphous silica particles (phytoliths and diatoms) are highly soluble 128 compared to the other soil silicates minerals around neutral pH (Fraysse et al., 2009). We 129 combined a solute budget at soil-plant scale for estimating the contribution of irrigation with 130 the $\mathrm{Si}$ isotopic compositions $\left(\delta^{30} \mathrm{Si}\right)$ of the various soil, plant and water compartments for 131 assessing the complementary Si sources. In order to decipher the plant-driven processes from 132 the water-soil interactions, the solute budget was performed in four different conditions: bare 133 plot, bare plot with addition of DE, rice plot and rice plot with DE addition. 


\subsection{Experimental set up}

136 The study took place at the VC Farm (Experimental farm of Mandya, Southern India which 137 depends on the University of Agricultural Sciences, Bengaluru, 12 34 '22'N, 76 49'38.5'E). 138 The soil is categorized as Typic Rhodustalfs, has a sandy loam texture, a $\mathrm{pH}$ of 7.1 and contains quartz, feldspar, goethite, kaolinite and illite clay minerals (see also Sandhya K. 2016 for further information for the soil composition). A paddy field was divided into 16 plots of 4 by $5 \mathrm{~m}\left(20 \mathrm{~m}^{2}\right)$, isolated from each other by furrows (Fig. 1) to prevent any drainage input/output from adjacent plot.

Each plot was inundated and ploughed. Then, four different experiments were set up, each with four replicates: (1) barren soil (further referred as "bare"), (2) barren soil with application of $30 \mathrm{~g} \mathrm{~m}^{-2}$ of diatom earth from Agripower Australia Ltd. (DE; further referred as "bare+DE") (3) planted with rice (further referred as "rice"), and (4) rice planted with application of $30 \mathrm{~g} \mathrm{~m}^{-2}$ of DE before planting (further referred as "rice+DE"). In rice and rice+DE plots, twenty one days old rice seedlings of species KMP-101, locally called Thanu, were transplanted with a spacing of $20 \mathrm{~cm}$ by $10 \mathrm{~cm}$. The total fertilizer applied was $27.2 \mathrm{~g} \mathrm{~m}^{-}$

2 of urea $\left(\mathrm{CH}_{4} \mathrm{~N}_{2} \mathrm{O}\right), 39 \mathrm{~g} \mathrm{~m}^{-2}$ of single superphosphate (SSP, $\left.\mathrm{Ca}\left(\mathrm{H}_{2} \mathrm{PO}_{4}\right)_{2}\right)$ and $10.4 \mathrm{~g} \mathrm{~m}^{-2}$ of muriate of potash (MOP, $\mathrm{KCl}$ ), corresponding respectively to $910 \mathrm{mmol} \mathrm{N} \mathrm{m}^{-2}, 248$ mmol P m${ }^{-2}$ and $140 \mathrm{mmol} \mathrm{K} \mathrm{m}^{-2}$. The entire dose of SSP, half dose of MOP and urea were applied prior to transplanting. Remaining MOP and urea were given as two splits at 30th and 60th days after transplanting. All plots were irrigated once in a week with the local borewell water for the 100 days duration of the experiment (22 ${ }^{\text {nd }}$ August to $16^{\text {th }}$ December 2015). The applied DE (Agripower Australia Ltd) contains amorphous silica particles (diatom frustules) and crystalline minerals (quartz, smectite, kaolinite).

\subsection{Water and plant sampling}

161 Water from the bore well used for irrigation was collected four times from March 2015 to

162 November 2016 for checking the stability of its chemical composition. Two soil pore water samplers $\left(\right.$ Rhizon $\left.{ }^{\circledR}\right)$ were installed in the center of each plot: one just below soil surface at

$1641 \mathrm{~cm}$ depth to collect infiltration water (considered as soil water input), the other at $40 \mathrm{~cm}$ depth to collect soil leaching (considered as soil output water). Samplers at $40 \mathrm{~cm}$ were installed prior to ploughing and their connection tube buried. To avoid disturbance of local 
soil properties, particularly preferential infiltration, connection tube was unearthed the day of transplanting, after ploughing. Shallow Rhizon samplers were inserted horizontally after transplanting. Soil pore waters were collected twice in a month $(n=6-9$ per plot, 33 to 36 samples per experiment) by suction with a $50 \mathrm{ml}$ syringe and stored in polypropylene bottles. Volume collected each time ranged from few $\mathrm{ml}$ to $50 \mathrm{ml}$. Unfortunately, we observed from chemical analyses that Rhizon samplers at $40 \mathrm{~cm}$ were collecting the local shallow groundwater, which composition is very close to the canal irrigation water used in the command area of the KRS dam (Meunier et al., 2015), instead of collecting soil leaching. As an alternative, four plots (one per experiment) were cored up to $20 \mathrm{~cm}$ depth to sample soil pore water not impacted by the local groundwater in November 2015, i.e. about one month before harvest. Cores were sliced in five sections $(0-2.5 \mathrm{~cm}, 2.5-5 \mathrm{~cm}, 5-10 \mathrm{~cm}, 10-15 \mathrm{~cm}$ and $15-20 \mathrm{~cm}$ ) and soil pore water extracted by centrifugation and/or hydraulic press when pore water content was too low for extraction by centrifugation. Few additional samples of stagnant water, from a previous experiment were also analyzed for comparison with Rhizon and core samples. Water chemistry was determined at the Indo-French Cell for Water Sciences, Indian Institute of Sciences, Bengaluru. Major anions and cations were analysed with an ion chromatograph (Metrohm) and silica using the molybdate blue method and a UVvisible Knauer detector. The overall precision obtained for the concentration measurements was better than $10 \%$. The reference materials used for the quality check was ION 96.4 and PERADE (Environment Canada). Plant biomass was harvested at plant maturity and weighed. Straw (leaves and stems) and grains with husk were dried and preserved for further chemical and isotopic analyses. Finally, one algal mat per experiment was collected to assess the presence of diatoms and check the isotopic composition of ground-surface soil ASi.

All of the data were analyzed statistically using one-way ANOVA with XLSTAT (Addinsoft) at a significance level of $\mathrm{P}<0.05$ via the Tukey test.

\subsection{Determination of plant Si and soil ASi}

Si concentration in plants was measured following the method described in Ma and Takahashi (2002). Briefly the rice plants were washed in distilled water before oven dried at $70^{\circ} \mathrm{C}$ for 2$3 \mathrm{~h}$ and finely grounded. Samples were digested in concentrated $\mathrm{HNO}_{3}, \mathrm{H}_{2} \mathrm{O}_{2}$ and $\mathrm{HF}$ using a microwave digestion system before dilution in $4 \%$ boric acid. The Si was determined using the molybdenum blue method at $600 \mathrm{~nm}$. The ASi soil pool was separated from the soil matrix (5g aliquot) using heavy liquid flotation. Carbonates were first removed with $\mathrm{HCl}$ (at $37 \%$ 
overnight), then the organic matter (OM) was oxidized with $\mathrm{H}_{2} \mathrm{O}_{2} 33 \%$ at $50-70{ }^{\circ} \mathrm{C}$. The clay

201 fraction was removed by decantation with sodium hexametaphosphate to ease deflocculation 202 and the heavy minerals by flotation using $\mathrm{ZnBr}_{2}$ dense liquor set at $\mathrm{d}=2.3 \mathrm{~g} \mathrm{~cm}^{-3}$. $\mathrm{ASi}_{\mathrm{zb}}$ 203 fraction should theoretically be composed of pure amorphous silica. However, this fraction 204 may contain some impurities, typically clays, which could impact the estimation of ASi stock 205 in soil and also alter the $\delta^{30} \mathrm{Si}$ signature of phytoliths. In order to assess the purity of $\mathrm{ASi}_{\mathrm{zb}}$ 206 samples and to correct if necessary $\mathrm{ASi}_{\mathrm{zb}}$ and $\delta^{30} \mathrm{Si}$ values, we used an index based on the 207 chemical composition of $\mathrm{ASi}_{\mathrm{zb}}$ fraction that considers $\mathrm{Al}$ as a proxy of clay contamination 208 (kaolinite or smectite) according to the equation:

$$
\mathrm{ASi}_{\mathrm{zb}} \text { purity }=(\mathrm{Si}-\mathrm{Al}) / \mathrm{Si}
$$

With $\mathrm{Si}$ and $\mathrm{Al}$ contents in $\mathrm{mol} \mathrm{kg}^{-1}$. The $\mathrm{ASi}_{\mathrm{zb}}$ purity of pure silica fraction should be one, pure kaolinite zero and Ca-smectite around 0.58. The concentration of Si from ASi can be calculated considering a mean water content in opal of $10 \%$ (Bartoli \& Wilding, 1980) equivalent to 0.37 moles of $\mathrm{H}_{2} \mathrm{O}$ for 2 moles of $\mathrm{SiO}_{2}$ and the purity index following the equation:

$$
\mathrm{ASi}=\mathrm{ASi}_{\mathrm{zb}} \cdot \mathrm{ASi}_{\mathrm{zb}} \text { purity } \cdot 0.42
$$

With 0.42 the conversion factor from opal to $\mathrm{Si}$.

\subsection{Solute mass balance at soil-plant scale}

The objective of solute Si mass balance at soil-plant scale is to assess where and how much dissolved silica (DSi) is removed from the system, which first requires a water budget. The total input water flux $\left(\mathrm{Q}_{\text {total }}\right)$ is composed of irrigation and rainfall. Irrigation flux (I) was quantified by measuring the yield of the borewell pump and by irrigating all plots for a same known duration. Rainfall (R) was measured with the manual rain gauge of the VFS farm. Estimation of the DSi flux leached from the soil requires estimating the leaching water flux $\left(\mathrm{Q}_{\text {soil output }}\right)$ which depends on the intensity of local evapotranspiration (ET). $\mathrm{Q}_{\text {soil output }}$ was assessed following two ways:

(1) Considering a simplified water balance. In absence of runoff, $\mathrm{Q}_{\text {soil output }}$ can be deduced from the relation $\mathrm{Q}_{\text {soil output }} \approx \mathrm{Q}_{\text {total }}-\mathrm{ET}=\mathrm{R}+\mathrm{I}-\mathrm{ET}$. In bare soil conditions, ET is expected to be similar to the potential evapotranspiration (PET). In paddy fields, the 
actual evapotranspiration $\left(\mathrm{ET}_{\mathrm{a}}\right)$ is known to exceed PET. For this reason, $\mathrm{ET}_{\mathrm{a}}$ is usually estimated by multiplying PET with a crop coefficient. Crop coefficient varies according to the local climatic conditions and along the cropping season. For the simplified water balance, we used the value of 1.15 , corresponding to the average crop coefficient of rice for semi-arid and moderate wind conditions, provided by FAO (Allen et al., 1998). This value is consistent with the estimates of Tyagi et al. (2000) in Northern India and more recently of Reddy et al. (2015) in Southern India. The local PET was assessed from solar radiation and temperature data for the 100 days of cropping period (data from the Karnataka State Natural Disaster Monitoring Centre, KSNDMC). This $\mathrm{Q}_{\text {soil output }}$ estimation is independent from chemical data.

(2) Using the solute mass balance of a conservative element. It relies on the hypothesis that the soil input flux of a conservative element is equal to the soil output flux (steady state hypothesis). A conservative behavior means that interactions with soil and plant are limited enough to be neglected and then, that its concentration in the soil layer only depends on the evapotranspiration intensity. This approach, classically used for estimating groundwater recharge in pristine watershed (e.g. Maréchal et al., 2009, 2011a,b; Fouépé et al., 2011), considers chloride as the conservative element and is then known as the chloride mass balance method (CMB). In most cases $\mathrm{Cl}$ is considered to originate only from atmospheric inputs. However, CMB was also applied with success in anthropic systems like urban watersheds (Fouépé Takounjou et al., 2011) or agriculture in a context similar to this study: a winter wheat plot fertilized with $\mathrm{KCl}$ for three decades (Tyner et al., 2000). Since in the present study it was not possible to monitor the soil pore water composition at $40 \mathrm{~cm}$ depth, $\mathrm{CMB}$ was applied for the first $20 \mathrm{~cm}$ of soil using the core pore water composition with, as main advantage, being able to assess the above-ground evaporation and to track, once in the soil, the progressive enrichment of $\mathrm{Cl}$ with depth by transpiration and compare it with the expected depletion of silica. The small scale CMB provides the opportunity to test the pertinence of sodium as conservative element, since $\mathrm{Na}$ is not brought by fertilizers nor involved in plant cycle. Above-ground evaporation was assessed for all four experiments by comparing the average $\mathrm{Cl}$ or $\mathrm{Na}$ concentration in $\mathrm{Q}_{\text {total }}$ with the average $\mathrm{Cl}$ or $\mathrm{Na}$ concentration in the infiltrating solution $(1 \mathrm{~cm}$ depth Rhizon sampler) according to the relationship: 


$$
\mathrm{Q}_{\text {AG evaporation }}=\mathrm{Q}_{\text {total }}-\frac{\overline{[N a, C l\rceil_{\text {borewell }} \cdot I+\overline{\left\lceil N a, C l \eta_{\text {rain }}\right.} \cdot R}}{\overline{\left[N a, C l l_{\text {surface }}\right. \text { porewater }}}
$$

With $\overline{\lceil\mathrm{Na}, \mathrm{Cl}\rceil_{\text {borewell }}}$ the average $\mathrm{Na}$ or $\mathrm{Cl}$ concentration in irrigation water $(\mathrm{n}=6)$,

$\overline{\lceil\mathrm{Na}, \mathrm{Cl}\rceil_{\text {rain }}}$ the average $\mathrm{Na}$ or $\mathrm{Cl}$ concentration in rain water, here taken from long term monitoring of the Mule Hole watershed $(\mathrm{n} \approx 200$; Riotte et al., 2014), and

$271 \overline{\lceil\mathrm{Na}, \mathrm{Cl}\rceil_{\text {surface porewater }}}$ the average $\mathrm{Na}$ or $\mathrm{Cl}$ concentration in the $1 \mathrm{~cm}$ depth pore water 272 collected with Rhizon sampler ( $\mathrm{n}=8$ to 9 per plot, 4 plots per experiment, then 32 to 36 samples per experiment). Water fluxes are specific, which means they are expressed per surface unit in $\mathrm{mm}$ or $\mathrm{L} / \mathrm{m}^{2}$. The water flux infiltrating in the soil can be deduced as:

$$
\mathrm{Q}_{\text {input }}=\mathrm{Q}_{\text {total }}-\mathrm{Q}_{\text {AG evaporation }}
$$

The specific water flux leached from the soil, $Q_{\text {output }}$, can be approximated for each experiment by simple mass balance, assuming that the soil input flux of the conservative element is equal to the soil output flux, which is the principle of the CMB method. Here, to be consistent with the soil output composition (core pore water at $15-20 \mathrm{~cm}$ ), the soil input composition considered for the calculation was the shallowest core pore water $(0-2.5 \mathrm{~cm})$ of each experiment. Then, $Q_{\text {output }}$ can be described as:

$$
\mathrm{Q}_{\text {output }}=\mathrm{Q}_{\text {input }} \cdot \frac{[\mathrm{Na}, \mathrm{Cl}]_{0-2.5 \mathrm{~cm} \text { porewater }}}{[\mathrm{Na}, \mathrm{Cl}]_{15-20 \mathrm{~cm} \text { porewater }}}
$$

Soil input and output DSi fluxes ( $\mathrm{FSi}_{\text {input }}$ and $\mathrm{FSi}_{\text {output, }}$, respectively) were estimated in a second step, by multiplying DSi concentrations in $1 \mathrm{~cm}$ and $15-20 \mathrm{~cm}$ pore waters, respectively, with the water fluxes estimated from ET or CMB approaches. The difference between input and output DSi fluxes $(\triangle \mathrm{FSi})$ provides an estimate of the apparent removal or addition DSi flux. This flux is considered as "apparent" because it may not account for the

292 entire Si flux mobilized or removed from the soil pore water. However, the $\delta^{30}$ Si signature of 293 this flux is expected to provide constrains on the water-soil-(plant) processes involved in the 294 soil. It can be assessed according to a simple isotopic mass balance equation: 


$$
\delta^{30} S i_{\Delta F S i}=\frac{F S i_{\text {output }} . \delta^{30} S i_{\text {output }}-F S i_{\text {input }} . \delta^{30} S i_{\text {input }}}{\Delta F S i}
$$

\section{$1.5 \quad \delta^{30}$ Si measurements}

299 The $\delta^{30} \mathrm{Si}$ signatures were determined on irrigation water, stagnant water $(\mathrm{n}=3)$, shallow $300(1 \mathrm{~cm})$ Rhizon pore water $(\mathrm{n}=4)$, core pore water depth profiles $(\mathrm{n}=25)$ and on solid silica 301 pools, i.e. DE, clay fraction, ASi of algal mats $(n=4)$, ASi of soils $(n=2)$ straw $(n=2)$ and - rice 302 grains with husk ( $\mathrm{n}=2$ ). Solid samples were first digested by alkaline fusion with $\mathrm{NaOH}$ and 303 dissolved in water and diluted $\mathrm{HCl}$, following the procedure of Zambardi and Poitrasson 304 (2011) modified from Georg et al. (2006). Both digested solid and dissolved samples were processes through Bio-Rad AG50-X12 ion exchange resin to remove the cationic matrix and elute the silica fraction. This latter was diluted to $2 \mathrm{mg} \mathrm{L}^{-1}$. Then, $1 \mathrm{mg} \mathrm{L}^{-1}$ of $\mathrm{Mg}$ was added as internal standard for online correction of mass bias during the analysis.

Isotopic measurements were performed on a Multi-Collector ICP-MS Neptune (Thermo $\left.{ }^{\circledR}\right)$ at medium resolution and replicated 3 times. The reference material NBS 28, also spiked with $1 \mathrm{mg} \mathrm{L}^{-1}$ of $\mathrm{Mg}$, was measured between each sample (bracketing mode). Isotopic data were normalized to the NBS 28 international standard and expressed in per mil (\%o) following the relation:

$\beta 13$

$$
\delta^{30} S i(\%)=\left(\frac{\left(\frac{{ }^{30} S i}{{ }^{28} S i}\right)_{\text {sample }}}{\left(\frac{{ }^{30} S i}{{ }^{28} S i}\right)_{N B S 28}}-1\right) .1000
$$

316 The uncertainty associated with the $\delta^{30} \mathrm{Si}$ data $(2 \sigma)$ corresponds to the relative standard 317 deviation obtained from the 3 replicates. The reproducibility was checked by regular 318 measurements of the reference material BHVO (a basaltic rock). The average $\delta^{30} \mathrm{Si}$ obtained 319 from 2010 to 2016 measurements, $-0.27 \pm 0.06 \%$ o $(n=24)$, matches the values obtained by 320 Zambardi and Poitrasson (2011), $-0.27 \pm 0.08 \%$ and Savage et al. (2012), $-0.30 \pm 0.09 \%$.

321 The standard deviation found for BHVO measurements $( \pm 0.06 \%$ ) will be considered as the 322 minimum precision of $\delta^{30} \mathrm{Si}$ data. 


\section{Results}

324

325

326

327

328

329

330

331

332

333

334

335

336

337

338

339

340

341

342

343

344

345

346

347

348

349

350

351

352

353

354

\subsection{Chemical composition of waters}

The composition of the borewell water was stable over the whole study period, $\mathrm{Cl}$ and $\mathrm{Na}$ concentrations $\left(3484 \pm 383 \mu \mathrm{mol} \mathrm{L}^{-1} ; 6215 \pm 360 \mu \mathrm{mol} \mathrm{L}^{-1}\right.$, Table 1) being within the range found in the region for groundwater located in semi-arid conditions and impacted by agriculture (Siva Soumya et al., 2013). Borewell water is also particularly rich in DSi, on average $1217 \pm 155 \mu \mathrm{mol} \mathrm{L} \mathrm{L}^{-1}$, as compared for instance to the Kaveri river, between 100 and $300 \mu \mathrm{mol} \mathrm{L}^{-1}$ (Meunier et al., 2015) or to the groundwater of a nearby forested watershed (Maréchal et al., 2011b). Such concentration should make irrigation water a significant Si source to plants. Sodium and Chloride concentrations of shallow Rhizon pore waters $(n=138)$ and stagnant water $(n=2)$ stretch on a linear relationship $\left(R^{2}=0.83\right.$ for all samples, $0.72<R^{2}$ $<0.93$ for the 16 individual plots), on which the borewell composition falls too. This trend reflects the common dilution (by rain) and concentration (by evaporation) cycles of both elements (Fig. 2a). On the contrary, DSi concentrations are always more diluted than the borewell, even at the highest $\mathrm{Na}$ concentrations. DSi ranges from $100 \mu \mathrm{mol} \mathrm{L}^{-1}$ (Fig. 2b), which correspond to the equilibrium with quartz, to $1000 \mu \mathrm{mol} \mathrm{L}{ }^{-1}$.

DSi concentrations in rice and rice+DE experiments are on average lower than in bare and bare+DE ones. Within the soil, the $\mathrm{Cl}$ and $\mathrm{Na}$ concentrations of core pore water samples increase with depth (Table 2, figure 3). DSi exhibits again a different pattern with sharp decrease to $\sim 100 \mu \mathrm{mol} \mathrm{L}^{-1}$ within the upper five centimeters in rice and rice+DE plots, and more regular decrease in bare and bare+DE plots (Fig. 3). Between 15 and $20 \mathrm{~cm}$ depth, DSi concentration of rice plots cannot be distinguished from those of bare plots.

\subsection{Water and solute mass balance}

The total amount of water received by each plot over the cultivation period (from transplantation to harvest) was $889 \mathrm{~mm}$, comprising $473 \mathrm{~mm}$ from bore well and $416 \mathrm{~mm}$ from rainfall. Considering a PET of $433 \mathrm{~mm}$ for this period and a crop coefficient for rice of 1.15 (Allen et al., 1998), the actual evapotranspiration in rice plots should be $500 \mathrm{~mm}$. In absence of surface runoff or lateral subsurface flow, the soil leaching flux would be $390 \mathrm{~mm}$ beneath rice plots, while it would be slightly higher, $455 \mathrm{~mm}$, in bare soils. 
Using equations of section 2.4 and either $\mathrm{Na}$ or $\mathrm{Cl}$ as conservative element, it was possible to distinguish the water and solute budgets both above-ground (in stagnant water, before infiltration) and below-ground (within soil). Above-ground evapotranspiration (Eq. 3) ranges from $370 \mathrm{~mm}$ in bare experiment to $410 \mathrm{~mm}$ in rice+DE experiment (Table 3). No difference was observed between Cl- and Na-based calculations. Both estimations agree with direct pan measurements made by Siva Sivapalan (2015) in similar climatic conditions and latitude. Water fluxes leached from the soil layer were assessed using $\mathrm{Cl}$ and $\mathrm{Na}$ concentrations measured in the deepest soil pore waters and Eq. 5. Sodium-based calculations provided homogeneous leaching water fluxes across experiments, from $180 \mathrm{~mm}$ (rice + DE) to $230 \mathrm{~mm}$ (rice), i.e. twice lower than those estimated from the water balance, while chloride-based leaching water fluxes were more scattered and ranged from 110 (rice + DE) to $460 \mathrm{~mm}$ (rice). Since DSi of stagnant water fluctuates over time due to concentration by evaporation or dilution by rain (Figure 2b), deducing the DSi flux removed at the ground surface from the average DSi concentration only would provide a value marred by a large uncertainty. Normalizing DSi to $\mathrm{Na}$ or $\mathrm{Cl}$ allows overcoming dilution and concentrations effects and then improving the precision associated to calculation of DSi removal. Average $\mathrm{Si} / \mathrm{Na}$ molar ratios a $1 \mathrm{~cm}$ depth of bare and bare+DE experiments are 0.128 and 0.124 , respectively, while they are slightly but significantly lower in rice and rice+DE experiments, 0.095 and 0.092, respectively according to the Tukey HSD test (Table 1). Standards deviations are about twice larger for $\mathrm{Si} / \mathrm{Cl}$, probably because of $\mathrm{KCl}$ additions, but remained narrower compared to the DSi fluctuations. The above-ground DSi removal calculated from $\mathrm{Na} / \mathrm{Si}$ ratios was 210 mmol. $\mathrm{m}^{-2}$ in bare and bare+DE experiments, and 275-280 $\mathrm{mmolSi} \mathrm{m}^{-2}$ in rice and rice+DE experiments. Similar values were obtained using $\mathrm{Si} / \mathrm{Cl}$ (Table 3). These results indicate that less than two third of the DSi flux brought by borewell irrigation to bare experiments and about half of DSi in rice experiments infiltrate into the ground; such proportion of aboveground DSi removal was unexpected and has, to our knowledge, never been reported before. By difference with the input DSi flux to each plot, the DSi flux infiltrating into the soil would be $410 \mathrm{mmolSi} \mathrm{m}^{-2}$ in bare and bare+DE experiments and $320 \mathrm{mmolSi} \mathrm{m}^{-2}$ in rice and rice+DE experiments. Soil leaching DSi fluxes, calculated using the deepest soil pore water compositions and leaching water fluxes, ranged from 27 to $55 \mathrm{mmolSi} \mathrm{m}^{-2}$ in rice experiment to 40 to $84 \mathrm{mmolSi} \mathrm{m}^{-2}$ in bare+DE experiment. This value is relatively low compared to the Si percolating flux calculated in humid tropical conditions (Philippines; Klotzbücher et al., 2015), because of the high percolating water flux. The DSi removal within the soil layer, 
calculated as the difference between soil DSi input and leaching fluxes, was slightly lower in rice experiments (190 to $235 \mathrm{mmolSi} \mathrm{m}^{-2}$ ) than in bare ones ( 250 to $310 \mathrm{mmolSi} \mathrm{m}^{-2}$ ).

\section{$2.3 \quad \delta^{30}$ Si of waters}

The $\delta^{30} \mathrm{Si}$ of the bore-well water, $1.49 \%$, falls in the upper part of the range observed up to now in groundwater (Frings et al., 2016), but it is similar to the values found in the groundwater of the Mule Hole watershed (0.81 to $1.49 \%$ ) located on the same peninsular gneissic complex as Mandya. This signature evolves towards heavy values, up to $4.39 \%$, as water stagnates and DSi drops. With the exception of one sample which exhibits a low $\delta^{30} \mathrm{Si}$ value $\left(1.89 \%\right.$ ) associated to high DSi $\left(849 \mu \mathrm{mol} \mathrm{L}{ }^{-1}\right)$, shallow $(1 \mathrm{~cm})$ soil pore water display heavy $\delta^{30} \mathrm{Si}$ ranging from 2.94 to $4.36 \%$ (Fig. 3). These signature slightly decrease with depth, down to 2.04 to $3.26 \%$ at $15-20 \mathrm{~cm}$. The $\delta^{30} \mathrm{Si}$ of these soil pore water are significantly heavier than those ever measured up to now (see review of Frings et al., 2016). On average, $\delta^{30} \mathrm{Si}$ of soil pore water is slightly lower in rice plots than in bare plots, but all pore waters evolve with depth within the same $\delta^{30} \mathrm{Si}$ range, whatever the experiment.

\subsection{Soil silica pools and $\delta^{30} \mathrm{Si}$}

The soils of the sub-humid and semi-arid zones of the Deccan plateau are known to be immature and still contain primary minerals like plagioclases and quartz (e.g. Braun et al., 2009). In Mandya, the $<2 \mu \mathrm{m}$ fraction of the soil, which includes clays sensus stricto and clay minerals like Fe-oxyhydroxides, accounts for only $21 \%$ which means that primary minerals and $\mathrm{ASi}$ compose about $80 \%$ of the soil. The soil $\mathrm{ASi}_{\mathrm{ZB}}$ fractions in rice and rice $+\mathrm{DE}$ plots, when corrected from impurities, are 1.9 and $1.8 \%$ (Table 4). Such ASi values are twice higher than in the Mule Hole forest, located in similar geological settings $(\sim 1 \%)$, or than in some other paddy fields (Desplanques et al., 2006). Taking into account the ASi $\mathrm{ZB}_{\mathrm{ZB}}$ fraction, the proportion of Si located in primary silicates would be at least $75 \%$.

The $\delta^{30} \mathrm{Si}$ of primary minerals can be assimilated to the whole bedrock signature $(-0.34 \%$ ) determined for the Mule Hole watershed. Soil clays of Mandya display $\delta^{30} \mathrm{Si}$ of $1.09 \pm 0.06 \%$, slightly heavier but close to the Mule Hole Ferralsol clays $(-1.3 \pm 0.15 \%$ o) This confirms that the fractionation factor $\left({ }^{30} \varepsilon\right)$ between bedrock and clay in this weathering context is lower than that predicted by models (Meheut et al., 2007) or measured in tropical (Ziegler et al., 2005) or boreal (Georg et al., 2007) soils. The slightly heavier $\delta^{30} \mathrm{Si}$ in 
420

421

422

423

424

425

426

427

428

429

430

431

432

433

434

435

436

437

438

439

440

441

442

443

444

445

446

447

448

449

450

451

452

Mandya's clay could however be explained by a minor contribution of silica adsorbed onto ferrihydrite in the clay-size fraction, since the granulometric fraction recovered contained more Fe than Si (Table 4). The $\delta^{30} \mathrm{Si}$ of soil $\mathrm{ASi}_{\mathrm{ZB}}$ fractions were corrected, when needed, from clay contribution using the purity index described in section 2.3. Correction consists in extrapolating the mixing curve between clay and ASi to a purity index of 1 (Fig. 4). Both $\mathrm{ASi}_{\mathrm{ZB}}$ compositions align on the same mixing curve which tends towards $\delta^{30} \mathrm{Si}$ of $0.5 \%$.

\subsection{ASi stock and $\delta^{30}$ Si of rice plants, algal mats and DE}

The rice biomass, Si content in rice and its $\delta^{30} \mathrm{Si}$ signature are presented in Table 5. Because root $\mathrm{Si}$ accounts for only few percent of the total Si taken up by rice plants (Ding et al., 2005; Sun et al., 2008), straw (stem and leaves) and whole grain (grain and husk) represent the bulk rice Si uptake. Average straw biomass and grain weights harvested in the four rice plots are $7.96 \pm 0.60$ tons $^{-1}$ and $6.12 \pm 0.26$ tons $^{-1} \mathrm{ha}^{-1}$, respectively. In the rice $+\mathrm{DE}$ plots, straw biomass is significantly higher, $10.3 \pm 0.5$ tons $^{-1}$, for a similar whole grain (grain + husk) yield as rice experiments, $6.33 \pm 0.71$ tons $\mathrm{ha}^{-1}$. Average straw Si contents in rice and rice $+\mathrm{DE}$ experiments are comparable, $4.72 \pm 0.72 \%$ and $5.77 \pm 0.30 \%$, respectively. These values fall in the upper side of the range found in China by Ding et al. (2005) but are twice higher than in Camargue (South of France; Desplanques et al., 2006). Whole grain Si contents (including husk), $0.55 \pm 0.09$ and $0.59 \pm 0.04 \%$, respectively, are also similar to the husk and grain values of Ding et al. (2005) and Sun et al. (2008). The average Si uptake in rice experiments, deduced from biomass and ASi data, are $377 \pm 81 \mathrm{~kg} \mathrm{ha}^{-1}\left(1.34 \pm 0.29 \mathrm{molSi} \mathrm{m}^{-2}\right)$ in straw and $33.3 \pm 6.3 \mathrm{~kg} \mathrm{ha}^{-1}\left(0.12 \pm 0.02 \mathrm{molSi} \mathrm{m}^{-2}\right)$ in grains, comparable to Desplanques et al. (2006) and in rice+DE experiments $595 \pm 54 \mathrm{~kg} \mathrm{ha}^{-1}\left(2.12 \pm 0.19 \mathrm{molSi} \mathrm{m}^{-2}\right)$ in straw and $37.5 \pm 4.5 \mathrm{~kg} \mathrm{ha}^{-1}\left(0.13 \pm 0.02 \mathrm{molSi} \mathrm{m}^{-2}\right)$ in grains. The Si uptake by the whole plants is then significantly higher in rice+DE experiments, $2250 \pm 180 \mathrm{mmolSi} \mathrm{m}^{-2}$, than in rice ones, $1460 \pm 270 \mathrm{mmolSi} \mathrm{m}^{-2}$. The $\delta^{30} \mathrm{Si}$ in rice compartments evolves from about $1 \%$ in the straw to $2 \%$ in the whole grain (Table ), in agreement with the enrichment of heavy isotopes observed in the highest parts of the plant (Ding et al., 2005; 2008, Sun et al., 2008; 2016). Bulk rice $\delta^{30} \mathrm{Si}$ of rice experiments, $1.29 \pm 0.07 \%$, is significantly different from the bulk rice of rice $+\mathrm{DE}$ experiments, $0.99 \pm 0.07 \%$. Both are $1 \%$ higher than the values observed up to now in rice, all close to $0 \%$ (Ding et al., 2005; 2008, Sun et al., 2008).

The $\mathrm{ASi}_{\mathrm{ZB}}$ corr fractions of the four algal mats (one per experiment) range between 0.7 (rice+DE) to $2.0 \%$ (bare+DE) (Table 4). Although the presence of few diatom frustules in 
algal mats was attested by scanning electron microscopy, the $\mathrm{ASi}_{\mathrm{ZB} \text { corr }}$ contents in algal mats is not significantly different from soils. One reason could be that because soil ASi is high, the algae bloom has little effect on the total ASi at soil surface. Three over the four $\delta^{30} \mathrm{Si}$ of algal mat $\mathrm{ASi}_{\mathrm{ZB}}$ fall within a mixing between clays and a range of $\mathrm{ASi}$ end-member from +0.5 to $+1.5 \%$ (Fig. 4), encompassing the straw $\delta^{30} \mathrm{Si}(+1 \%$ ). In absence of pure algae analysis, some uncertainty remains on the $\delta^{30} \mathrm{Si}$ of algal mat $\mathrm{ASi}_{\text {ZBcorr. }}$.

\section{Discussion}

\subsection{Validation of $\mathrm{Na}$ - and Cl-based mass balances}

462 The high DSi and $\mathrm{Na}$ concentrations in the bore-well makes irrigation the unique solute source ( $>99 \%$ ) of these elements to the plot (Table 2). Bore-well represents also the dominant source of $\mathrm{Cl}(93 \%)$ and makes the $\mathrm{KCl}$ contribution marginal ( $6 \%)$ although this latter is still 12 times higher than the rainwater contribution $(0.5 \%)$. Such situation is representative of the intensive agriculture context in Peninsular India, which relies massively on bore-well irrigation since two decades (Shah, 2014) and is responsible for the degradation of groundwater quality (Siva Soumya et al., 2013; Buvaneshwari et al., 2017). Applying CMB method in this context is unusual, as in most systems studied up to now it was considered that $\mathrm{Cl}$ originates only from the atmosphere (Dettinger 1989, Maréchal et al., 2009) or from $\mathrm{KCl}$ (Tyner et al., 2000). Since bore well water composition was stable over the duration of the experiment, the $\mathrm{Si}, \mathrm{Cl}$ and $\mathrm{Na}$ input fluxes to each plot could be precisely determined. In the stagnant water (above-ground samples and 1cm-deep Rhizons of all experiments), the covariation of $\mathrm{Cl}$ and $\mathrm{Na}$ concentrations reflects the evaporation/dilution cycles of the irrigation water (Fig. 2a) and cannot be explained by interactions with soil particles nor plants. Then, above the ground the conservative behavior of $\mathrm{Cl}$ and $\mathrm{Na}$ is validated, confirming their pertinence for estimating the evaporation at the ground surface (Eq. 3) and the DSi removal from stagnant water.

479 Soil pore waters could be recovered only once during the reproducing stage, i.e. when the rice 480 plants had grown up, which is a possible limitation of the approach. Taken as a whole, 481 chemical composition of pore waters displays a $\mathrm{Na}$ vs $\mathrm{Cl}$ relationship more scattered than for 482 surface waters. Moreover, the deepest pore waters from the rice experiments plot above the 483 area defined by above-ground waters (Fig. 2c). This relative Na-enrichment can be explained 484 by $\mathrm{Na}$ addition and/or a $\mathrm{Cl}$ removal from pore water combined with high evapotranspiration. 
Since the main source of $\mathrm{Na}$ in local soils is Na-plagioclase (Riotte et al., 2014), $\mathrm{Na}$ addition

486 would imply a slight but significant weathering of this primary mineral in rice experiments.

487 Alternatively, a combination of partial $\mathrm{Cl}$ removal by plant uptake with high 488 evapotranspiration would be consistent with (1) the evapotranspiration intensity at the period 489 of coring which is known to be maximum at this crop stage III (reproductive; e.g. Tyagi et al., 490 2000) and (2) the soil-to-plant transfer of chloride of 5\% and the Cl concentrations in above491 ground rice biomass, from $0.14 \mathrm{~g} \mathrm{~kg}^{-1}$ dry wt in polished rice to $4.8 \mathrm{~g} \mathrm{~kg}^{-1}$ in roots (Tsukada 492 and Takeda, 2008). While it was not possible to quantify the extent of $\mathrm{Na}$ addition and/or $\mathrm{Cl}$ 493 removal, the soil pore water compositions at least indicate that in rice experiments $\mathrm{Na}$ and/or $494 \mathrm{Cl}$ are not conservative. The main consequence for the solute mass balance within the soil 495 layer of this experiment should be an underestimation (Na-based) or an overestimation (Cl496 based) of soil leaching water flux. Indeed, Cl-based and Na-based soil leaching fluxes, 457 497 and $229 \mathrm{~mm}$ respectively, flank the value deduced from actual evapotranspiration, $391 \mathrm{~mm}$. 498 Although the relative uncertainty on the soil leaching water flux is large, the incidence on the 499 Si solute budget is limited because of the low DSi concentrations of deep soil pore waters. 500 According to the calculation of water flux, soil leaching Si flux in the rice experiment range 501 only from 30 to $55 \mathrm{mmolSi} \mathrm{m}{ }^{-2}$. Then, the DSi flux removed from the soil layer, calculated by 502 difference between DSi soil input and output would only range within 210 and 240 503 mmolSi $\mathrm{m}^{-2}$, under the conditions which this mass balance was performed, i.e. in absence of 504 monitoring of soil pore water composition. To summarize, $\mathrm{Na}$ and $\mathrm{Cl}$ exhibit conservative 505 behaviors above the ground but not within the soil layer of rice experiments. Nevertheless, 506 because $\mathrm{Na}$ and $\mathrm{Cl}$ behave in opposite ways, the former slightly added to the system and the 507 latter slightly removed, they can provide a range for the soil leaching water flux. The 508 precision associated to a solute budget within the soil layer, deduced from $\mathrm{Na}$ and $\mathrm{Cl}$ mass 509 balance, shall mostly depend on the difference between input and output DSi concentrations.

\subsection{Controls of DSi and $\delta^{30}$ Si- DSi above the ground surface}

512 Solute budgets indicate that above-ground processes affect DSi mass balance of all 513 experiments, with different intensities for bare and rice experiments but no visible influence 514 of DE addition. Two processes could be envisaged for explaining above-ground DSi removal 515 in bare plots, diatom uptake and/or adsorption on Fe-oxyhydroxides. Since soil Si pools are 516 large compared to the DSi flux removed during a cropping season, none of these processes is 517 expected to significantly change the size or the isotopic composition of soil pools. For 
instance, if DSi removal would only originate from diatom blooms, the algal mat would contain at best $10 \%$ more ASi than the soil if the sample collected at the ground surface would be $3 \mathrm{~mm}$ thick. Such a limited increase lies within the incertitude of ASi determination and prevents quantification of this process, although few diatom frustules were observed by scanning electron microscope. An alternative way to assess the importance of diatom uptake and/or adsorption on Fe-oxyhydroxides is to consider the kinetics of these processes. In batch experiments with solid/liquid ratio as low as $1 / 250$ and similar initial DSi concentration, Delstanche et al. (2009) observed that $40 \%$ of DSi is absorbed onto Ferrihydrite after 72 hours and $25 \%$ onto Goethite after 500 hours. In paddy field conditions where the solid/liquid ratio is ten to hundred times higher than in this batch experiment, DSi removal rate should increase in same proportions as the solid/liquid ratio and induce a drop in DSi within few hours after irrigation.

530 During these experiments, the level of DSi in 1 cm-Rhizons or above-surface samples was nearly always depleted compared to the borewell, even when waters were collected soon after irrigation. The intensity and rate of DSi removal is visible when DSi is compared to $\mathrm{Na}$ concentrations (Fig. 2b): for most samples, DSi drops while $\mathrm{Na}$ remains at the borewell concentration. For instance, a 30\% DSi depletion was observed within the $100 \mathrm{~m}$-long open channel separating the bore-well from the experimental plots, during a previous experiment (the channel was replaced by a pipe avoid Si depletion by delivering irrigation water directly to the plot, Fig. 2b) which attests that DSi depletion is almost immediate and incompatible with the timescale of diatom growth, typically few days whatever the temperature, nutrient and light conditions (e.g. Litchman et al., 2003; Schabhüttl et al., 2013).

The DSi removal above the ground surface fractionates $\mathrm{Si}$ isotopes according to an isotopic fractionation factor $\left({ }^{30} \varepsilon\right)$ that depends upon the process at stake. For instance, ${ }^{30} \varepsilon$ induced by diatom uptake (-1.12 $\pm 0.2 \%$, Alleman et al., 2005; $-1.04 \pm 0.08 \%$, Opfergelt et al., 2011) and adsorption onto ferrihydrite $(-1.08 \pm 0.06 \%$, Delstanche et al., 2009) induce smaller isotopic fractionation than $\mathrm{Si}$ adsorption onto goethite (-1.62 $\pm 0.24 \%$; Delstanche et al., 2009). Thanks to the solute mass balance (see section 3.2), the residual fraction of DSi in above-ground water could be estimated for each sample and the ${ }^{30} \varepsilon$ of above-ground DSi removal deduced graphically using the initial borewell composition, the DSi- $\delta^{30} \mathrm{Si}$ and the residual fractions of DSi. Residual fractions of DSi were calculated by three ways, (1) considering $\mathrm{Na}$ as conservative element (Fig. 5a), (2) considering $\mathrm{Cl}$ as conservative element (Fig. 5b) and (3) directly from the DSi fraction (Fig. 5c). It can be seen from Fig. 5 that 
${ }^{30} \varepsilon$ vary slightly according to the way residual fraction is calculated. However, several consistent insights can be drawn from these graphs. First, data fit better a Rayleigh model than a steady state one, particularly bare experiments which display higher $\mathrm{DSi}-\delta^{30} \mathrm{Si}$ than rice ones and larger isotopic fractionation factors, between -1.5 to $-2.5 \%$ depending on residual fraction calculation (considering the $1 \mathrm{~cm}$ rhizon of bare experiment (B) as an outlier in Fig. $5 \mathrm{a}$ and $5 \mathrm{~b}$ ). These values confirm that the evolution of DSi and DSi- $\delta^{30} \mathrm{Si}$ above the ground surface cannot be explained by diatom uptake. Indeed, the fast decrease of DSi above the ground even led in several samples to isotopic fractionations even larger than those expected from adsorption onto goethite. This could be linked to the kinetics itself that would enhance preferential removal of light isotopes compared to ${ }^{30} \mathrm{Si}$. Second, in rice experiments the apparent isotopic fractionation factors were smaller than in bare ones and ranged between -1 (value for rice; Ding et al.; 2008) and $-1.5 \%$, which means that in rice and rice+DE experiments both plant uptake and adsorption compete for DSi removal. Since the ${ }^{30} \varepsilon$ of DSi removal in rice experiments is close to $-1 \%$ (value for rice plant), it is likely that plant uptake dominates DSi removal. Therefore, it will be assumed in the further discussion that aboveground plant uptake ranges from 140 to $270 \mathrm{mmolSi} \mathrm{m}^{-2}$. Third, in agreement with the above ground-surface DSi solute mass balance (Table 3), the DE application did not impact the DSi above-ground budget nor $\mathrm{DSi}-\delta^{30} \mathrm{Si}$ which confirms that above-ground processes do not involve soil particles dissolution.

In regions covered with paddy fields, irrigation water is transported by canal from the river to the paddy fields located at the highest topographical position and then passes by gravity through many terraces before returning to the river. It is then likely that interactions of irrigation water with the succession of soil surfaces should amplify the Si adsorption onto Feoxy-hydroxides. According to the batch experiments of Delstanche et al. (2009), the fraction of DSi removed by adsorption onto Fe-hydroxides depends on the initial DSi concentration. In the case of goethite, the fraction adsorbed is inversely proportional to the initial DSi, and can reach $>70 \%$ when initial DSi is $210 \mu \mathrm{mol} \mathrm{L}^{-1}$ (lowest initial DSi tested by these authors), against $45 \%$ for an initial DSi of $1290 \mu \mathrm{mol} \mathrm{L}^{-1}$. Although the trend is less clear for ferrihydrite experiments, DSi adsorption still accounts for more than $60 \%$ for the lowest initial DSi concentration. According to the compilation from Gaillardet et al. (1999), DSi of major rivers rarely exceeds $200 \mu \mathrm{mol} \mathrm{L}{ }^{-1}$, the world average being only $127 \mu \mathrm{mol} \mathrm{L}^{-1}$. Low 
where paddy fields are irrigated by surface water. In this context, our field experiments and the adsorption experiments of Delstanche et al. (2009) provide an alternative or at least additional explanation for the heavy $\delta^{30} \mathrm{Si}$ observed in Asian rivers like the Yangtze River (Ding et al., 2004), the Nile River (Cockerton et al., 2013) or some tributaries of the Ganga (Fontorbe et al., 2013, Frings et al., 2015) where paddy fields and wetlands are widespread. The extreme $\delta^{30} \mathrm{Si}$ values downstream the Yangtze River for instance, up to 3.7\%o, fall within the range observed in the $1 \mathrm{~cm}$ rhizons and above-surface waters of our experiments. If they were assigned to plant uptake in paddy fields and wetlands by Ding et al. (2004), we suggest here that these $\delta^{30} \mathrm{Si}$ values result at least partly from Si absorption onto soil particles. In these regions, both processes contribute to large DSi removal from aquatic systems, unlike what is observed in temperate climate for instance (Clymans et al., 2011). More detailed studies would be needed to estimate the respective roles of adsorption and plant uptake on extreme riverine $\delta^{30} \mathrm{Si}$ values in basins where paddies and/or wetlands are widespread.

\subsection{Controls of DSi and $\delta^{30}$ Si- DSi within the soil}

600 Depending of leaching calculation methods, the DSi flux leached from the $20 \mathrm{~cm}$ topsoil layer 601 ranges from 30-55 $\mathrm{mmolSi} \mathrm{m}^{-2}$ (rice) to 40-80 $\mathrm{mmolSi} \mathrm{m}^{-2}$ (bare+DE) (Table 3), which overall corresponds to 5 to $15 \%$ of the initial DSi supply to each plot. DSi leaching from bare $+\mathrm{DE}$ and rice $+\mathrm{DE}$ experiments are slightly higher than from bare and rice experiments, indicating that the DE applied may have contributed to DSi budget and plant uptake in the $20 \mathrm{~cm}$ topsoil layer. Such values are nearly three orders of magnitude lower than those proposed by Nguyen et al. (2016) from HYDRUS modeling in a Vietnamese crop experiment but closer to the solute balance performed by Klotzbücher et al. (2015) in Philippines, i.e. more humid climate than Mandya. The apparent DSi flux removed from the soil layer $(\Delta \mathrm{FSi}$, corresponding to the difference, in Table 3, between soil input and soil output) is paradoxically higher in bare and bare+DE experiments (275-325 and 255-300 mmolsi m${ }^{-2}$, respectively) than in rice and rice+DE experiments (210-240 and 190-245 mmolSi m${ }^{-2}$, respectively). However, if one includes the additional 140 to $270 \mathrm{mmolSi} \mathrm{m}^{-2}$ taken up by rice plant above soil surface (see previous section), the $\Delta \mathrm{FSi}$ values are equivalent for all

614 experiments. As for the above-ground balance, this does not mean that the processes 615 responsible for the DSi removal in bare and rice experiments are the same.

616 In bare experiments, the smooth decrease of DSi with depth corresponds to a process 617 occurring along with water percolation, such as DSi adsorption and clay minerals 
618 precipitation. However, according to the Si isotopic fractionation factors estimated up to now 619 for DSi adsorption $\left({ }^{30} \varepsilon=-1 \%\right.$; Delstanche et al., 2009; Opfergelt et al., 2009) or clay 620 minerals formation $\left({ }^{30} \varepsilon=-1\right.$ to $-2 \%$; Ziegler et al., 2005; Georg et al., 2007; Méheut et al., 621 2007), these two processes should have depleted the residual soil pore water in light $\mathrm{Si}$ 622 isotopes and then induce an increase of $\delta^{30} \mathrm{Si}-\mathrm{DSi}$. Instead, $\delta^{30} \mathrm{Si}$ decreased by about $1 \%$ 623 between soil surface and $15-20 \mathrm{~cm}$ depth. The theoretical $\delta^{30} \mathrm{Si}$ associated to the DSi removal $624\left(\delta^{30} S i_{\triangle F S i}\right.$, calculated with Eq. 6) in bare and bare+DE experiments would then range from 3.70 to $3.84 \%$ and from 4.53 to $4.80 \%$ (Table 3 ), respectively; i.e. 0.1 to $0.4 \%$ higher than the $\delta^{30} \mathrm{Si}$ of the input flux. Such signatures are incompatible with the signatures measured in 627 the soil silica pools, which suggests that Si removal is not the unique process controlling DSi and $\delta^{30} \mathrm{Si}-\mathrm{DSi}$ in the soil. The $\delta^{30} \mathrm{Si}-\mathrm{DSi}$ values points to concomitant, isotopically light silica release from soil particles like $\mathrm{Si}$ desorption (then partial isotopic exchange during DSi adsorption) or mineral dissolution. Desorption would mean silica exchange with the adsorbed pool of $\mathrm{Si}$ of the soil. Since the isotopic signature of the exchangeable pool cannot be determined, the extent of this process cannot be assessed. However, its effect on $\delta^{30} \mathrm{Si}-\mathrm{DSi}$ was already suspected during an adsorption experiment performed on lateritic soils of Cameroon (Opfergelt et al., 2009). The soil silicates susceptible to weather and release silica encompass primary minerals (quartz, Na-plagioclase), secondary clay minerals and opal (ASi). According to the saturation indexes calculated by PHREEQS, quartz and clay minerals would be stable but soil pore waters would be undersaturated regarding to ASi (-0.5 to -0.7) and Na-plagioclase (-13 to -15 assuming $\mathrm{Al}$ concentration of $1 \mathrm{ppm}$ ). Na-plagioclase weathering could be consistent with the Na excess observed in soil pore waters (Fig. 2c), but both ASi dissolution and Na-plagioclase weathering are expected to contribute to soil DSi.

641 In rice experiments, the DSi drop just below ground-surface to values as low as $100 \mu \mathrm{mol} \mathrm{L}{ }^{-1}$ 642 or less, was also observed in hydroponic conditions (Ding et al., 2008). Both $\mathrm{Na}$ and $\mathrm{Cl}$ 643 concentrations increase while DSi decreases which confirms that Si uptake by the rice plant is 644 predominantly selective and then occurs via an active mechanism (e.g. Sun et al., 2016). 645 Because of the Si uptake efficiency, the plants could bring pore water DSi concentration low 646 enough to modify the saturation regarding soils minerals. In several samples DSi was for 647 instance lower than saturation with quartz $\left(100 \mu \mathrm{mol} \mathrm{L}^{-1}\right)$. The few pore waters recovered by 648 hydraulic press (labelled "HP" in Table 2) systematically exhibited lower concentration than 649 centrifuged ones; the water located in the smallest pores, where roots are more susceptible to 
650 take up nutrients, are indeed more Si depleted than in macro-pores. It is then possible that the 651 undersaturation with soil minerals is more pronounced in these pores than in macro porosity.

\section{$652 \quad 3.4 \quad$ Isotopic mass balance of rice and possible Si sources}

653 Estimating the $\mathrm{Si}$ sources to rice plant is possible because the cumulated uncertainty 654 associated to adsorption and soil leaching flux has a little impact on the estimation of DSi 655 contribution to plant uptake, which ranges from 25 to $35 \%$ in rice experiments and from 15 to $65623 \%$ in rice+DE ones. The soil pool contributing to plant uptake can be assessed once 657 deduced in this latter the contribution of irrigation DSi. If the total silica taken up by the rice 658 plant $\left(\mathrm{FSi}_{\text {plant }}\right)$ is considered as mix of silica coming from irrigation water $(\Delta \mathrm{FSi})$ and from 659 soil mineral weathering, its isotopic composition can be described as:

660

$$
\delta^{30} S i_{\text {plant }}=\frac{\Delta D S i . \delta^{30} S i_{F \Delta D S i}+\left(F S i_{\text {plant }}-F \Delta D S i\right) \cdot \delta^{30} S i_{\text {soil pool }}}{F S i_{\text {plant }}}
$$

662

663

where $\delta^{30} \mathrm{Si}_{\mathrm{F}_{\triangle} \mathrm{DSi}}$ is the $\delta^{30} \mathrm{Si}$ of irrigation DSi taken up by plants. This isotopic signature can be

664 roughly estimated if one assumes that its evolution during uptake follows a Rayleigh model, 665 which is a working hypothesis, by the relationship:

666

667

$$
\delta^{30} S i_{F \Delta \mathrm{DSi}}=\delta^{30} S i_{\text {borewell }}{ }^{30} \varepsilon_{\text {rice }} \cdot f_{F \Delta D S i} \cdot \frac{\ln \left(f_{F \Delta D S i}\right)}{1-f_{F \Delta D S i}}
$$

668

Where $f_{F \triangle D S i}$ is the fraction of DSi remaining in soil pore water after plant uptake:

670

$$
f_{F \Delta D S i}=\frac{F D S i_{\text {borewell }}-F D S i_{\text {plant uptake }}}{F D S i_{\text {borewell }}}
$$

673 According to the ranges of DSi uptake estimated for each experiment, $f_{F \triangle D S i}$ of rice 674 experiment would span from 0.06 to 0.34 and $f_{F \Delta D S i}$ of rice+DE from 0.05 to 0.39 . The $675 \delta^{30} \mathrm{Si}_{\mathrm{F} \Delta \mathrm{DSi}}$ associated to DSi uptakes (Eq. 8), using the ${ }^{30} \varepsilon_{\text {rice }}$ range from -0.4 to $-1 \%$ (Sun et 676 al., 2016), would be equivalent for rice and rice+DE experiments, from 0.93 to $1.42 \%$ and 
from 0.89 to $1.43 \%$, respectively. Then, the isotopic signature of the complementary soil source to the plant $\left(\delta^{30} S i_{\text {soil pool }}\right)$ can be estimated according to the equation:

$$
\delta^{30} S i_{\text {soil pool }}=\frac{F S i_{\text {plant }} \cdot \delta^{30}{ }_{S i} \text { plant }-\Delta F S i . \delta^{30} S i_{\Delta F S i}}{F S i_{\text {plant }}-\Delta F S i}
$$

The $\delta^{30} S i_{\text {soil pool }}$ of rice and rice+DE experiments would then range from 1.22 to $1.41 \%$ and from 0.75 to $1.01 \%$, respectively. Accordingly, the complete isotopic mass balance of Si at the soil-plant scale can be summarized (Fig. 6).

These heavy isotopic signatures confirm that clay and primary minerals do not significantly contribute to plant-Si. Without discarding a slight contribution of particle desorption, of which the $\delta^{30} \mathrm{Si}$ cannot be measured or assessed, the closest $\delta^{30} \mathrm{Si}$ among soil Si pools and most likely soil source would then be soil ASi. This finding is indeed consistent with the saturation index of soil pore water regarding to opal (see previous section) and with the dissolution rate of ASi; According to batch experiments performed by Fraysse et al, (2009), phytolith dissolution rates at circum neutral $\mathrm{pH}$ are several order of magnitude higher than those of kaolinite or plagioclase. It is then likely that the relative excess of $\mathrm{Na}$ compared to $\mathrm{Cl}$ in soil pore water would rather correspond to a slight $\mathrm{Cl}$ depletion. The isotopic fingerprint of ASi in rice plant confirms the role of this specific soil pool as source of Si in rice, as proposed by some authors from solute mass balance (e.g. Desplanques et al., 2006). However, it should be stressed that contrary to Camargue or other places where irrigation DSi is low and rice straw removed from field, leading to ASi depletion in these soils, the soil ASi contents in soils of our study were remarkably high because of local practices. In our context, the risk of ASi depletion in soils is limited, although rice cultivation is intensive. The $\delta^{30} \mathrm{Si}$ of rice plants is sensitive to the most available $\mathrm{Si}$ of the soil, as illustrated by the $\delta^{30} S i_{\text {soil pool }}$ of both experiments that do no overlap with values in rice+DE experiment about $-0.3 \%$ lower than those of rice one. The amount of Si applied by DE corresponds to only $14 \%$ of biomass-Si in rice $+\mathrm{DE}$ and does not explain the $54 \%$ difference with rice experiment. But the $\delta^{30} \mathrm{Si}$ of DE, $0.36 \%$, was contrasted enough to slightly influence the isotopic signature of biomass in rice $+\mathrm{DE}$. Then, it is likely that $\mathrm{DE}$ was at least partly incorporated by the plant as a supplementary source of $\mathrm{Si}$ and played a role of priming effect, as for $\mathrm{N}$ fertilizer (e.g. Jenkinson et al., 1985; Kuzyakov et al., 2000), which induced a higher Si uptake by the plant. 
The main implication of this isotopic mass balance is that rice could be able to take Si from a solid source (ASi) without significant isotopic fractionation. Finally, replicating such experiments in conditions of low silica availability (ASi-poor soils and irrigation with low DSi water) would probably reveal a different distribution of silica sources to the plant.

\section{Conclusion}

714 By combining data on water, soil and plants we have shown that Si isotopic signatures are useful for constraining the dynamics of $\mathrm{Si}$ in a paddy fields. A significant DSi removal occurred very soon after plot irrigation consistent with adsorption in bare soils. Within the soil layer, pore water DSi and $\delta^{30} \mathrm{Si}$ exhibited a sharp decrease in rice experiments which illustrated the active DSi uptake by rice within the soil. The DE application was also traced by a slightly lighter $\mathrm{Si}$ isotope signature in the soil solution. At the field scale, our results puts constraints for a better understanding on the effects of soil Si application. At the global scale, the results highlight a possible DSi sink in wetlands, even in not vegetated areas, that could be responsible of the high $\delta^{30} \mathrm{Si}$ observed in some tropical rivers.

\section{Acknowledgements}

The study was supported by the Indo-French Centre for the Promotion of Advanced Research (IFCPAR/CEFIPRA; Project $\mathrm{n}^{\circ} 5109-1$ ) and the French Institute for Research and Development (IRD, France) which funded deputation of J. Riotte and long duration stays of J.D. Meunier. The authors thank the two anonymous reviews for their useful comments on the manuscript. Hemanth Moger and Jean-Louis Duprey are thanked for the chemical analyses, Jonathan Prunier and Manuel Henry for their support in clean room and the personnel of VC farm at Mandya for their help during the rice cropping experiment.

\section{References}

733 Alexandre A, Meunier J D, Colin F and Koud J M 1997 Plant impact on the biogeochemical

734 cycle of silicon and related weathering processes. Geochim. Cosmochim. Acta, 6, 677-682

735 Alleman L Y, Cardinal D, Cocquyt C, Plisnier P D, Descy JP, Kimirei I, Sinyinza D and

736 André L 2005 Silicon isotopic fractionation in Lake Tanganyika and its main tributaries. J.

737 Great Lakes Res. 31, 509-519

738 Allen P A 1997 Earth surface processes (p. 404). Oxford: Blackwell. 
Allen R G, Pereira L S, Raes D and Smith M 1998 Crop evapotranspiration: guidelines for computing crop water requirements. FAO Irrigation and Drainage Paper 56. (FAO, Rome, 1998), $326 \mathrm{p}$

Anupama K, Prasad S and Reddy C S (2014) Vegetation, land cover and land use changes of the last 200 years in the Eastern Ghats (southern India) inferred from pollen analysis of sediments from a rain-fed tank and remote sensing, Quat. Int., 325, 93-104

Bartoli F, and Wilding L P 1980 Dissolution of Biogenic Opal as a Function of its Physical and Chemical Properties. Soil Sci. Soc. Am. J. 44, 873-878. doi:10.2136/sssaj1980.03615995004400040043x

Brenchley W E and Maskell E J 1927 The inter-relation between silicon and other elements in plant nutrition. Ann. Appl. Biol. 14, 45-82

Buvaneshwari S, Riotte J, Sekhar M, Mohan Kumar M S, Sharma A K, Duprey J L, Audry S, Giriraja P R, Yerabham P, Moger H, Durand P, Braun J J and Ruiz L 2017 Groundwater resource vulnerability and spatial variability of nitrate contamination: insights from high density tubewell monitoring in a hard rock aquifer. Sci. Tot. Env., 579, 838-847 Braun J J, Descloitres M, Riotte J, Fleury S, Barbiero L, Boeglin J L, Violette A, Lacarce E, Ruiz L, Sekhar M, Mohan Kumar M S, Subramanian S and Dupré B 2009 Regolith mass balance inferred from combined mineralogical, geochemical and geophysical studies: Mule Hole gneissic watershed, South India. Geochim. Cosmochim. Acta 73, 935-961

Cardinal D, Gaillardet J, Hughes H J, Opfergelt S and André L 2010 Contrasting silicon isotope signatures in rivers from the Congo Basin and the specific behaviour of organic-rich waters. Geophys. Res. Lett. 37, doi:10.1029/2010GL043413

Cary L, Alexandre A, Meunier J D, Boeglin J L and Braun J J 2005 Contribution of phytoliths

762 to the suspended load of biogenic silica in the Nyong basin rivers (Cameroon).

763 Biogeochem.74, 101-114

764 Cheng B T 1982 Some significant functions of silicon to higher plants. J. Plant Nutr. 5, 13457651353

766 Clymans W, Struyf E, Govers G, Vandevenne F and Conley D J 2011 Anthropogenic impact 767 on biogenic Si pools in temperate soils. Biogeosciences 8, 2281-2293

768 Cockerton H E, Street-Perrott F A, Leng M J, Barker PA, Horstwood M S A and Pashley V 7692013 Stable-isotope (H, O, and $\mathrm{Si}$ ) evidence for seasonal variations in hydrology and $\mathrm{Si}$ 
770

771

772

773

774

775

776

777

778

779

780

781

782

783

784

785

786

787

788

789

790

791

792

793

794

795

796

797

798

799

800

cycling from modern waters in the Nile Basin: implications for interpreting the Quaternary record. Quat. Sci. Rev. 66, 4-21

Crooks R and Prentice P 2016 Extensive Investigation Into Field Based Responses to a Silica Fertiliser. Silicon 9, 301-304, DOI: 10.1007/s12633-015-9379-3

Datnoff L E and Rodrigues F A 2005 The role of silicon in suppressing rice diseases. APS net Feature Story, 1-28, http://www.apsnet.org/online/feature/silicon/

Delstanche S, Opfergelt S, Cardinal D, Elsass F, André L and Delvaux L 2009 Silicon isotopic fractionation during adsorption of aqueous monosilicic acid onto iron oxide. Geochim. Cosmochim. Acta, 73, 923-934

Demarest M S, Brzezinski M A and Beucher C P 2009 Fractionation of silicon isotopes during biogenic silica dissolution. Geochim. Cosmochim. Acta, 73, 5572-5583

Derry L A, Kurtz A C, Ziegler K and Chadwick O A (2005) Biological control of terrestrial silica cycling and export fluxes to watersheds. Nature, 433, 728-731

Desplanques V, Cary L, Mouret J C, Trolard F, Bourrie G, Grauby O and Meunier J D 2006 Silicon transfers in a rice field in Camargue (France). J. Geochem. Explor. 88, 190-193

Dettinger M D 1989 Reconnaissance estimates of natural recharge to desert basins in Nevada, USA, by using chloride-balance calculations. J. Hydrol. 106, 55-78

Dietrich D, Hinke S, Baumann W, Fehlhaber R, Bäucker E, Rühle G, Wienhaus O. and Marx G 2003 Silica accumulation in Triticum aestivum L. and Dactylis glomerata L. Anal. Bioanal. Chem. 376, 399-404

Ding T, Wan D, Wang C and Zhang F 2004 Silicon isotope compositions of dissolved and suspended matter in the Yangtze River, China. Geochim. Cosmochim. Acta 68, 205-216

Ding T, Ma G, Shui M, Wan D and Li R 2005 Silicon isotope study on rice plants from the Zhejiang province, China. Chem. Geol. 218, 41-50

Ding T, Tian S H, Sun L, Wu L H, Zhou J X and Chen ZY 2008 Silicon isotope fractionation between rice plants and nutrient solution and its significance to the study of the silicon cycle. Geochim. Cosmochim. Acta 72, 600-615

Fontorbe G, De La Rocha C, Chapman H J and Bickle M J 2013 The silicon isotopic composition of the Ganges and its tributaries. Earth Planet. Sci. Lett. 381, 21-30

Fouépé Takounjou A, Ndam Ngoupayou J R, Riotte J, Takem G E, Mafany G, Maréchal J C and Ekodeck G E 2011 Estimation of groundwater recharge of shallow aquifer on humid 
801 environment in Yaoundé, Cameroon using hybrid water fluctuation and hydrochemistry 802 methods. Environ. Earth. Sci., 64, 107-118

803 Fraysse F, Pokrovsky O S, Schott J and Meunier J D 2009 Surface chemistry and reactivity of 804 plant phytoliths in aqueous solutions. Chem. Geol. 258, 197-206

805 Frings P J, Clymans W and Conley D J 2014 Amorphous silica transport in the Ganges basin: 806 Implications for Si delivery to the oceans. Proc. Earth Planet. Sci. 10, 271-274

807 Frings P J, Clymans W, Fontorbe G, Gray W, Chakrapani G J, Conley D J and De La Rocha 808 C L 2015 Silicate weathering in the Ganges alluvial plain. Earth Planet. Sci. Lett. 427, 136809148

810 Frings P J, Clymans W, Fontorbe G, De La Rocha C L and Conley C L 2016 The continental 811 Si cycle and its impact on the ocean Si isotope budget. Chem. Geol. 425, 12-36

812 Gaillardet J, Dupré B, Louvat P and Allègre C J 1999 Global silicate weathering and $\mathrm{CO}_{2}$ 813 consumption rates deduced from the chemistry of large rivers, Chem. Geol. 159, 3-30

814 Georg R B, Reynolds B C, Frank M and Halliday A N 2006 Mechanisms controlling the 815 silicon isotopic compositions of river waters. Earth Planet. Sci. Lett. 249, 290-306

816 Georg R B, Reynolds B C, West A J, Burton K W and Halliday A N 2007 Silicon isotope 817 variations accompanying basalt weathering in Iceland. Earth Planet. Sci. Lett. 261, 476-490

818 Guntzer F, Keller C and Meunier J D 2012 Benefits of plant silicon for crops: a review. 819 Agronomy Sust. Dev. 32, 201-213

820 Henriet C, Bodarwé L, Dorel M, Draye X and Delvaux B 2008 Leaf silicon content in banana 821 (Musa spp.) reveals the weathering stage of volcanic ash soils in Guadeloupe. Plant and Soil, 822 313, 71-82, DOI 10.1007/s11104-008-9680-7

823 Hughes H J, Sondag F, Cocquyt C, Laraque A, Pandi A, André L and Cardinal D 2011 Effect 824 of seasonal biogenic silica variations on dissolved silicon fluxes and isotopic signatures in the 825 Congo River. Limnol. Oceanogr., 56, 551-561

826 Hughes H J, Sondag F, Santos R V, André L and Cardinal D 2013 The riverine silicon isotope 827 composition of the Amazon Basin. Geochim. Cosmochim. Acta 121, 637-651

828 Irfan K, Trolard F, Shahzad T, Cary L, Mouret JC and Bourrié G 2017 Impact of 60 Years of 829 Intensive Rice Cropping on Clay Minerals in Soils Due to Si Exportation. American Journal 830 of Agriculture and Forestry 5, 40-48

831 Jenkinson D S, Fox R H and Rayner J H 1985 Interactions between fertilizer nitrogen and soil 832 nitrogen- the so-called 'priming' effect. Eur. J. of Soil Sci. 36, 425-444 
833 Klotzbücher T, Leuther F, Marxen A, Vetterlein D, Horgan F G and Jahn R 2015 Forms and

834 fluxes of potential plant-available silicon in irrigated lowland rice production (Laguna, the 835 Philippines). Plant and Soil DOI 10.1007/s11104-015-2480-y

836 Kuzyakov Y, Friedel J K and Stahr K 2000 Review of mechanisms and quantification of 837 priming effects. Soil Biology \& Biochemistry, 32, 1485-1498

838 Liang Y, Nikolic M, Belanger R, Haijun G and Song A 2015 Silicon in Agriculture. From 839 Theory to Practice. Dordrecht: Springer

840 Litchman E, Steiner D and Bossard P 2003 Photosynthetic and growth responses of three 841 freshwater algae to phosphorus limitation and daylength. Freshwater Biology, 48, 2141-2148

842 Lucas Y 2001 The role of plants in controlling rates and products of weathering: Importance 843 of Biological pumping. Annu. Rev. Earth Planet. Sci. 29, 135-163

844 Ma J F and Takahashi E 2002 Soil, fertilizer, and plant silicon research in Japan. Elsevier, $845 \quad$ Amsterdam. 281p

846 Makabe S, Kakuda K, Sasaki Y, Ando T, Fujii H and Ando H 2009 Relationship between 847 mineral composition or soil texture and available silicon in alluvial paddy soils on the 848 Shounai Plain, Japan. Soil Sci. Plant Nutr. 55, 300-308

849 Maréchal J C, Murari R R V, Riotte J, Vouillamoz J M, Mohan Kumar M S, Ruiz L, Muddu S 850 and Braun J J 2009 Indirect and direct recharges in a tropical forested watershed: Mule Hole, 851 India. J. Hydrol. 364, 272-284

852 Maréchal J C, Braun J J, Riotte J, Bedimo Bedimo J P and Boeglin J L 2011a Hydrological 853 Processes of a Rainforest Headwater Swamp from Natural Chemical Tracing in Nsimi 854 Watershed, Cameroon. Hydrol. Process. 25, 2246-2260

855 Maréchal J C, Riotte J, Lagane C, Subramanian S, Kumar C, Ruiz L, Audry S, Murari V and 856 Braun JJ 2011b Chemical groundwater outputs from a small drainage watershed: Mule Hole, 857 South India. Appl. Geochem. 26, S94-S96

858 Méheut M, Lazzeri M, Balan E and Mauri F 2007 Equilibrium isotopic fractionation in the 859 kaolinite, quartz, water system: prediction from first-principles density-functional theory. 860 Geochim. Cosmochim. Acta 71, 3170-3181

861 Meunier J D, Guntzer F, Kirman S and Keller C 2008 Terrestrial plant-Si and environmental 862 changes. Miner. Mag. 72, 263-267 
863

864

865

866

867

868

869

870

871

872

873

874

875

876

877

878

879

880

881

882

883

884

885

886

887

888

889

890

891

892

893

Meunier J D, Riotte J, Braun J J, Muddu S, Chalié F, Barboni D and Saccone L 2015 Controls of DSi in streams and reservoirs along the Kaveri River, South India. Sci. Tot. Env. 502, 103113

Meunier J D, Barboni D, Anwar-ul-Haq M, Levard C, Chaurand P, Vidal V, Grauby O, Huc R, Laffont-Schwob I, Rabier J and Keller C 2017 Effect of phytoliths for mitigating water stress in durum wheat. New Phytol, 215: 229-239. doi:10.1111/nph.14554

Nguyen N M, Dultz S, Picardal F, Bui A T K, Pham Q V, Dam T T N, Nguyen C X, Nguyen N T and Bui H T 2016 Simulation of silicon leaching from flooded rice paddy soils in the Red River Delta, Vietnam. Chemosphere, 145, 450-456

Opfergelt S, de Bournonville G, Cardinal D, André L, Delstanche S and Delvaux B 2009 Impact of soil weathering degree on silicon isotopic fractionation during adsorption onto iron oxides in basaltic ash soils, Cameroon. Geochim. Cosmochim. Acta. 73, 7226-7240

Opfergelt S, Eiriksdottir E S, Burton K W, Einarsson A, Siebert C, Gislason S R and Halliday A N 2011 Quantifying the impact of freshwater diatom productivity on silicon isotopes and silicon fluxes: Lake Myvatn, Iceland. Earth Planet. Sci. Lett. 305, 73-82

Opfergelt S. and Delmelle P. (012 Silicon isotopes and continental weathering processes: Assessing controls on Si transfer to the ocean. C. R. Geoscience 344, 723-738

Pati S, Pal B, Badole S, Hazra G C and Mandal B 2016 Effect of Silicon Fertilization on Growth, Yield, and Nutrient Uptake of Rice, Commun. Soil Sci. Plant Anal., 47, 284-290

Piperno D R 1988 Phytolith Analysis: An Archaeological and Geological Perspective. Academic Press, San Diego, 280 p

Reddy K C, Arunajyothy S and Mallikarjuna P 2015 Crop Coefficients of Some Selected Crops of Andhra Pradesh. J. Inst. Eng. India Ser. A, 96, 123-130

Riotte J, Maréchal J C, Audry S, Kumar C, Bedimo J P, Ruiz L, Sekhar M, Cisel M, Chitra Tarak R, Varma M R R, Lagane C, Reddy P and Braun J J (2014) Vegetation impact on stream chemical fluxes: Mule Hole watershed (South India). Geochim. Cosmochim. Acta 145, $116-138$

Sandhya K. 2016 Biogeochemistry of silicon in different rice ecosystems of Karnataka. Ph.D. Thesis, Univ. Agric. Sci., Bengaluru, Karnataka, India

Savage P.S., Georg R.B., Williams H.M., Turner S., Halliday A.N. and Chappell B.W.(2012 ( The silicon isotope composition of granites. Geochim. Cosmochim. Acta, 92, 184-202 
894 Savant N K, Datnoff L E and Snyder G H 1997 Depletion of plant available silicon in soils: A 895 possible cause of declining rice yields, Comm. Soil Sci. Plant Anal., 28, 1245-1252

896 Schabhüttl S, Hingsamer P, Weigelhofer G, Hein T, Weigert A and Striebel M 2013 897 Temperature and species richness effects in phytoplankton communities. Oecologia, 171, 898 527-536. DOI 10.1007/s00442-012-2419-4

899 Seyfferth A L, Kocar B D, Lee J A and Fendorf S 2013 Seasonal dynamics of dissolved 900 silicon in a rice cropping system after straw incorporation. Geochim. Cosmochim. Acta 123, $901 \quad 120-133$

902 Shah T. 2014 Groundwater Governance and Irrigated Agriculture. Stockholm, Sweden: 903 Global Water Partnership, Technical Committee (TEC).. 71p. (TEC Background Papers 19) 904 doi:10.1080/09614520701469427

905 Siva Sivapalan 2015 Water Balance of Flooded Rice in the Tropics, Irrigation and Drainage 906 Sustainable Strategies and Systems, Muhammad Salik Javaid (Ed.), InTech, DOI: $907 \quad 10.5772 / 59043$

908 Siva Soumya B, Sekhar M, Riotte J, Banerjee A and Braun J J 2013 Characterization of 909 groundwater chemistry under the influence of lithologic and anthropogenic factors along a 910 climatic gradient in Upper Cauvery basin, South India. Env. Earth Sci., 69, 2311-2335

911 Struyf E, Smis A, Van Damme S, Garnier J, Govers G, Van Wesemael B, Conley D J, 912 Batelaan O, Frot E, Clymans W, Vandevenne F, Lancelot C, Goos P and Meire P 2010 913 Historical land use change has lowered terrestrial silica mobilization. Nat. Comm. 1, 129

914 Sun L, Wu L H, Ding T P and Tian S H 2008 Silicon isotope fractionation in rice plants, an 915 experimental study on rice growth under hydroponic conditions. Plant and Soil 304, 291-300. 916 DOI 10.1007/s1 11 04-008-9552-1

917 Sun Y, Wu L H and Li X 2016 Experimental Determination of Silicon Isotope Fractionation 918 in Rice. PLoS ONE 11(12): e0168970. doi:10.1371/journal.pone.0168970

919 Tyagi N K, Sharma D K and Luthra S K 2000 Determination of evapotranspiration and crop 920 coefficients of rice and sunflower with lysimeter. Agri. Water Manag. 45, 41-54

921 Tyner J. S., Brown G. O., Vogel J. R., Garbrech J. 2000 Chloride mass balance to determine 922 water fluxes beneath KCl-fertilized crops. Trans. ASABE 43, 1553-1559 923 doi:10.13031/2013.3055 
924 Vandevenne F I, Struyf E, Clymans W and Meire P 2012 Agricultural silica harvest: have 925 humans created a new loop in the global silica cycle? Frontiers in Ecology and the 926 Environment, 10, 243-248, doi:10.1890/110046

927 Vandevenne F I, Barão L, Ronchi B, Govers G, Meire P, Kelly E F and Struyf E 2015a 928 Silicon pools in human impacted soils of temperate zones. Global Biogeochem. Cycles, 29, 929 doi:10.1002/2014GB005049

930 Vandevenne F I, Delvaux C, Hughes H J, André L, Ronchi B, Clymans W. Barão L, Cornelis $931 \mathrm{~J}$ T, Govers G, Meire P and Struyf E 2015b Landscape cultivation alters $\delta^{30}$ Si signature in 932 terrestrial ecosystems. Scientific reports, 5: 7732, DOI: 10.1038/srep07732

933 Zambardi T and Poitrasson F 2011 Precise Determination of Silicon Isotopes in Silicate Rock 934 Reference Materials by MC-ICP-MS. Geostandards and Geoanalytical Res., 35, 89-99

935 Ziegler K, Chadwick O A, White A F and Brzezinski M A $2005 \delta^{30}$ Si systematics in a granitic 936 saprolite, Puerto Rico. Geology 33, 817-820 